This item was submitted to Loughborough's Research Repository by the author.

Items in Figshare are protected by copyright, with all rights reserved, unless otherwise indicated.

\title{
Decision-based forecast evaluation of UK interest rate predictability
}

PLEASE CITE THE PUBLISHED VERSION

http://dx.doi.org/10.1002/for.2369

PUBLISHER

(c) Wiley

VERSION

AM (Accepted Manuscript)

PUBLISHER STATEMENT

This work is made available according to the conditions of the Creative Commons Attribution-NonCommercialNoDerivatives 4.0 International (CC BY-NC-ND 4.0) licence. Full details of this licence are available at: https://creativecommons.org/licenses/by-nc-nd/4.0/

\section{LICENCE}

CC BY-NC-ND 4.0

\section{REPOSITORY RECORD}

Sirichand, Kavita, and S.G. Hall. 2019. "Decision-based Forecast Evaluation of UK Interest Rate Predictability". figshare. https://hdl.handle.net/2134/19754. 


\title{
Decision-Based Forecast Evaluation of UK Interest Rate Predictability
}

\author{
Kavita Sirichand* \\ Loughborough University \\ Stephen G. Hall ${ }^{\dagger \ddagger}$ \\ University of Leicester
}

April 28, 2015

\begin{abstract}
This paper illustrates the importance of density forecasting and forecast evaluation in portfolio decision making. The decision making environment is fully described for an investor seeking to optimally allocate her portfolio between long and short Treasury Bills, over investment horizons of up to two years. We examine the impact of parameter uncertainty and predictability in bond returns on the investor's allocation and we describe how the forecasts are computed and used in this context. Both statistical and decision-based criteria are used to assess the predictability of returns. Our results show sensitivity to the evaluation criterion used and in the context of investment decision making under an economic value criterion, we find some potential gain for the investor from assuming predictability.
\end{abstract}

Keywords: optimal portfolio choice, density forecasting, return predictability, parameter uncertainty and forecast evaluation.

JEL Classifications: C32, C53, E43, E47, G11.

\footnotetext{
${ }^{*}$ Corresponding author. School of Business and Economics, Loughborough University, Loughborough, LE11 3TU, UK; telephone: +44 01509222731 and email: k.sirichand@lboro.ac.uk.

${ }^{\dagger}$ Department of Economics, University of Leicester, Leicester, LE1 7RH, UK; email: s.g.hall@le.ac.uk.

${ }^{\ddagger}$ The authors give thanks to Kevin Lee, Giorgio Valente, Kalvinder Shields, Emi Mise, Wojciech Charemza, Chris Brooks and Gary Koop for their help. Stephen Hall would like to acknowledge the support of ESRC Grant Number RES-062-23-1753.
} 


\section{Introduction}

Conventionally forecast accuracy is assessed using statistical measures, which are usually based on point forecasts and some measure of the forecast errors, however these measures convey little information about the value of the forecast. Work by Leitch and Tanner (1991), Granger and Pesaran (2000) and Pesaran and Skouras (2004) asserts that given forecasts are ultimately intended to inform decision making they should be evaluated in the decision making context for which they are intended. In light of this, decision-based forecast evaluation ${ }^{1}$ is becoming increasingly popular, where forecasts are assessed from the forecast user's perspective using measures like profit and utility.

Predictability in asset returns and decision-based forecast evaluation in the context of investment decision making is examined by those including West et al (1993), Pesaran and Timmermann (1995), Marquering and Verbeek (2004), Thornton and Valente (2012) and Fuertes and Olmo (2013). ${ }^{2}$ Barberis (2000) finds if returns are predictable and not i.i.d. then horizon effects may in fact be observed ${ }^{3}$, and further the importance of parameter uncertainty is highlighted with the investor who ignores estimation risk over allocating to the risky asset. ${ }^{4}$ Studies that use decision-based criteria to evaluate the predictive power of theory informed models include Abhyankar, Sarno and Valente (2005, henceforth ASV), who find exchange rate predictability to significantly alter the optimal allocation and evidence of economic value to exchange rate predictability; further evidence is provided by Garratt and Lee (2009, henceforth GL) who also incorporate model uncertainty. Della Corte, Sarno and Thornton (2008, henceforth DST) present support for the Expectations Hypothesis of the term structure of interest rates under an economic value measure.

However, the literature that examines asset return predictability and the economic value of this predictability focus their attention on stock returns and exchange rates, with little attention being paid to interest rate predictability. This is what we seek to address here. Previous research concerned with assessing interest rate predictability largely use statistical evaluation criteria to compare forecasts generated from models that make differing assumptions regarding predictability. ${ }^{5}$ In this paper we consider first, how the allocation decisions of the investor are influenced by parameter uncertainty and predictability. Second, if a utility maximising investor gains, in terms of higher wealth, from assuming returns are predictable and using a model informed by economic fundamentals to forecast interest rates, as opposed to assuming they are not predictable and using a

\footnotetext{
${ }^{1}$ We use the terms economic value measures and decision-based measures interchangeably.

${ }^{2}$ See also Xia (2001), Avramov (2002), Brooks and Persand (2003), Boudry and Gray (2003), Han (2010) and Cenesizoglu and Timmermann (2012).

${ }^{3}$ Contrary to the early findings of Samuelson (1969) and Merton (1969) who show that if returns are i.i.d. then an investor with power utility has an optimal allocation that is insensitive to the investment horizon.

${ }^{4}$ Barberis models stock returns as (1) i.i.d. under the assumption of no predictability and (2) in a VAR under the assumption of predictability. Under i.i.d. returns the mean and variance evolve linearly. Barberis highlights that allocations will differ under (1) and (2) because the variance of the cumulative returns grow slower/faster than linearly with the investment horizon when predictability/parameter uncertainty is considered.

${ }^{5}$ See Fama (1990), Hafer et al (1992), Gosnell and Kolb (1997), Fauvel et al (1999), Diebold and Li (2006), De Pooter et al (2007) and Guidolin and Timmermann (2009).
} 
random walk model, in that we use decision-based forecast evaluation to assess if there is economic value to interest rate predictability.

The findings of ASV, DST and GL illustrate that the conclusion of how well the forecasts of models that assume predictability and are informed by economic fundamentals perform, compared to models of no predictability like the random walk, is sensitive to the evaluation criterion used. To be precise, under statistical measures no predictability models like the random walk are difficult to beat, but under decision-based methods encouraging evidence in favour of predictability is found.

When considering interest rate predictability, we turn to the leading theory of the term structure, the Expectations Hypothesis (EH), which postulates that the long term rate is a weighted average of expected future short term rates. In their key study Campbell and Shiller (1991) consider if the yield spread of the term structure has predictive power for future interest rate changes. The explanatory power of the EH has been examined extensively, with empirical support for the EH found to be sensitive to the dataset, time period considered and testing method employed. However, many report a strong comovement between the actual spread and the spread predicted by the $\mathrm{EH}$, thereby making it difficult to reject a hypothesis that is economically significant. ${ }^{6}$ Here we use a Multivariate VAR in Transformed Interest Rates (MVART) model, which embeds the cointegrating relations between the yields as implied by the EH, to capture predictability.

The contributions of this paper are empirical. We consider asset return predictability and the economic value of this predictability in the context of interest rates, and to our knowledge DST is the only other. Our work differs from DST in several ways; they focus on testing the $\mathrm{EH}$ and seeing if there is economic value to departures from the $\mathrm{EH}$. We however, use an unrestricted VAR, i.e. the MVART model, since we do not seek to test the EH. We are concerned firstly with our models' ability to forecast out-of-sample and secondly with the effects of parameter uncertainty and predictability on the optimal allocation, neither of which DST consider.

In brief, we compute the optimal portfolio allocation for a buy-and-hold investor with power utility over terminal wealth, using weekly data for the UK during 1997 week 10 to 2007 week 19, for two assets the 1-month and the $n$-month T-bill for $n=3,6,12$ months, over investment horizons of up to 2 years. The assets considered here provide risk-free returns and only differ in their maturity. We consider two models that make opposing assumptions regarding return predictability. If the investor believes returns are not predictable, she uses a random walk with drift model to forecast returns and inform her allocation decisions. If she believes that returns are predictable she uses the MVART model. Using these two models we examine the impact of predictability and parameter uncertainty on portfolio allocation, and further see if there are significant gains to an investor in terms of wealth from assuming returns are predictable and given by the MVART model. We do not take into account transactions costs and our work is based on the asset allocation framework used in Barberis (2000), ASV and GL. Both

\footnotetext{
${ }^{6}$ Other key studies include Taylor (1992), Cuthbertson (1996), Cuthbertson et al (1996, 2003), Longstaff (2000) and Sarno et al (2007).
} 
statistical and decision-based criteria are used to evaluate the out-of-sample forecasting performance of the models. Two types of uncertainty are considered here, future and parameter. $^{7}$ Initially parameter uncertainty is ignored, however potentially insignificant standard errors may imply that the true forecasting ability of the estimated coefficients may be weaker than that suggested by the coefficient estimates, Barberis (2000). Hence, by accommodating parameter uncertainty an improvement in the portfolio decision may be observed.

We find that an investor allocates differently when she assumes predictability to one who assumes that returns are not predictable. Further, the results under the statistical and decision-based criteria do not entirely coincide, with the evidence in favour of predictability being different under each criterion.

We recognise that it may be unlikely that an investor will have a portfolio consisting only of T-bills, however, we use this illustrative strategy to ascertain the effect of predictability and parameter uncertainty on allocation decisions, and determine if there is economic value to interest rate predictability.

The setup of this paper is as follows: Section 2 provides details of how the interest rates are modelled, the investment decision and the framework used to evaluate the economic value of predictability; Section 3 describes the dataset, the estimated models and provides a statistical forecast evaluation of each model; in Sections 4 and 5 we analyse the effects of predictability and parameter uncertainty on the optimal allocations and judge the models' forecasting performance by comparing their realised end-of-period wealth, and Section 6 concludes.

\section{Allocation, Parameter Uncertainty and Predictability}

We examine how a utility-maximising investor allocates her portfolio between 1-month and 3-, 6-, or 12-month T-bills and consider if there are gains in utility for an investor who believes returns are predictable and employs a model informed by economic fundamentals to forecast interest rates. Here we describe the models and the decision-based measure used.

\subsection{Modelling the Interest Rate}

The EH in a linearised form, see Campbell and Shiller (1991), states that the return on a $n$-period zero coupon bond should equal the return on a rolling investment in a sequence of $k m$-period bonds, where the integer $k=n / m$ and $n>m$, plus a time invariant term premium/liquidity premium $c^{(n, m)}$ :

$$
r_{t}^{(n)}=\frac{1}{k}\left[\sum_{i=1}^{k} E_{t}\left(r_{t+(i-1) m}^{(m)}\right)\right]+c^{(n, m)}
$$

\footnotetext{
${ }^{7}$ Where future uncertainty is that surrounding forecasts which is the result of unobserved future shocks. Parameter uncertainty for a given model, is that "concerned with the robustness of forecasts to the choice of parameter values" Garratt, Lee, Pesaran and Shin (2006, pp. 153).
} 
That is, the long rate is given by an average of the expected future short rates plus a liquidity premium. Further, the EH can be formulated as:

$$
s_{t}^{(n, m)}=\sum_{i=1}^{k-1}\left(\frac{k-i}{k}\right) E_{t}\left(\Delta r_{t+i m}^{(m)}\right)+c^{(n, m)}
$$

which describes the spread by expected future changes in the short rate. That is, aside from the constant premium, the spread is a reflection of the expected change in the short term rates over the life of the long bond. If the yields share a common stochastic trend, then we should find $(q-1)$ cointegrating vectors, as implied by stationary bivariate spreads, in a set of $q$ non-stationary yields. This is one method by which the validity of the $\mathrm{EH}$ is tested.

Assuming that yields are difference stationary and there exists a cointegrating relationship between $n$ - and $m$-period yields, such that spreads are stationary, then there exists a Wold representation which can be approximated by the following $\operatorname{VAR}(p)$ model:

$$
\mathbf{x}_{t}=\mu+\mathbf{B}_{1} \mathbf{x}_{t-1}+\mathbf{B}_{2} \mathbf{x}_{t-2}+\ldots+\mathbf{B}_{p} \mathbf{x}_{t-p}+\epsilon_{t}
$$

where in this multivariate case $q=4$ with $\mathbf{x}_{t}=\left(s_{t}^{(12,1)}, s_{t}^{(6,1)}, s_{t}^{(3,1)}, \Delta r_{t}^{(1)}\right)^{\prime}$. This $\operatorname{VAR}(p)$ is denoted the Multivariate VAR in Transformed Interest Rates (MVART) model, and describes the change in the $m$-period rate and the spread between the $n$ - and $m$-period yields using past changes and spreads.

The EH can be further tested by imposing restrictions on the MVART model. ${ }^{8}$ Here we do not impose such a stringent structure, but use the MVART model that embeds the cointegration as implied by the EH to explain and capture the UK term structure and in turn forecast the yields. As such, if the investor believes bill returns are predictable she employs the MVART model to forecast future returns.

In contrast, if however the investor believes that returns are not predictable, the random walk with drift (RW) model is used to forecast returns. In this case the $\operatorname{VAR}(p)$, equation (3), has $\mathbf{x}_{t}=\left(\Delta r_{t}^{(12)}, \Delta r_{t}^{(6)}, \Delta r_{t}^{(3)}, \Delta r_{t}^{(1)}\right)^{\prime}$ and no predictor variables hence $\mathbf{B}_{i}=0$ and $\Delta r_{t}^{(n)}=\mu+\epsilon_{t}$.

By modelling T-bill returns in these two ways allows us to examine whether it is beneficial to the investor, in terms of wealth gains, to assume that returns are predictable as opposed to assuming they are not. Both the RW and the MVART models are estimated when parameter uncertainty, which is the uncertainty about the true values of the model's parameters, is both ignored and accounted for. ${ }^{9}$

\footnotetext{
${ }^{8}$ Such that the spreads are determined in accordance to the EH. That is, the restrictions impose the EH structure on the VAR, see Campbell and Shiller (1991).

${ }^{9}$ We differentiate between when the model is estimated subject to stochastic uncertainty only and when it is estimated subject to stochastic and parameter uncertainty, by denoting them as RW and MVART, and RWPU and MVARTPU respectively.
} 


\subsection{Investment Strategies}

The buy-and-hold investor faces the problem of how to optimally allocate her wealth over a $H$ month investment horizon between $m$ - and $n$-month T-bills. Where $r_{t}^{(n)}$ and $r_{t}^{(m)}$ are the annualised, continuously compounded nominal zero coupon yields on $m$ - and $n$-month bills respectively.

If $H=n$, then the investment horizon is equal to the asset with the longest maturity considered, so the investor allocates the proportion $\omega$ of her initial wealth in a sequence of $m$-month bills and $(1-\omega)$ in a single $n$-month bill. If $H>n$ then the investor allocates $\omega$ in a sequence of $m$-month bills and $(1-\omega)$ in a sequence of $n$-month bills. That is, she invests $\omega$ in a sequence of $s=H / m$ rolling investments in short $m$-period bills and $(1-\omega)$ in a sequence of $l=H / n$ long $n$-period bills. Assuming that initial wealth is $W_{T}=1$, then the cumulative return at the end of the investment period $W_{T+H}$ is:

$$
W_{T+H}=\omega\left\{\exp \left(\frac{1}{s} \sum_{i=1}^{s} r_{T+(i-1) m}^{(m)}\right)\right\}+(1-\omega)\left\{\exp \left(\frac{1}{l} \sum_{i=1}^{l} r_{T+(i-1) n}^{(n)}\right)\right\}
$$

If $H=n$, then the return from the investment in the long $n$-period bill is known with certainty ${ }^{10}$, such that $E_{T}\left(r_{T}^{(n)}\right)=r_{T}^{(n)}$ and $W_{T+H}$ can be found by setting $H=n$ in equation (4). Into this decision making process risk aversion can be incorporated, using the end-of-horizon wealth $W_{T+H}$ from the standard constant relative risk aversion (CRRA) power utility function ${ }^{11}$, the utility is:

$$
v(W)=\frac{W^{1-A}}{1-A}
$$

where $A$ is the coefficient of risk aversion. The investor faces the following optimisation problem in $T$ :

$$
\max _{\omega} E_{T}\left(v\left(W_{T+H}(\omega)\right) \mid \Omega_{T}\right)
$$

where the investor computes the expectation above conditional upon the information set available at $T$. That is, the investor maximises the expected utility with respect to the proportion of the portfolio allocated to $m$-month bills.

Assessment of the above strategy requires expectations of $v\left(W_{T+H}(\omega)\right)$ to be formed based on the information available at $T$. Due to the non-linear nature of $W_{T+H}$ the entire joint probability distribution of the forecast values of $r_{T+(i-1) m}^{(m)}$ and $r_{T+(i-1) n}^{(n)}$, where $i=1$ to $s$, or $l$ respectively, is required over the $H$ period investment horizon to evaluate $E_{T}\left(v\left(W_{T+H}(\omega)\right) \mid \Omega_{T}\right){ }^{12} \quad$ From which the expected utility can be calculated for each possible proportion, and the optimal allocation is that which yields the maximum expected utility.

\footnotetext{
${ }^{10}$ In this sense the long $n$-period return is riskless, but the return from the rolling investments in $\mathrm{m}$ period bills are risky since future short rates are unknown. However, when $H>n$ then the cumulative returns from both the $n$ - and $m$-period investments will contain unknown future returns.

${ }^{11}$ See Campbell and Viceira (2003, pp. 24 and 42) for details on the properties of the CRRA utility function.

${ }^{12}$ It can be shown that the expected value of a non-linear variable is a function of its mean, variance and covariance, i.e. $E\left(\exp \left(t^{\prime} X\right)\right)=\exp \left(t^{\prime} \mu+\frac{1}{2} t^{\prime} \Sigma t\right)$.
} 
Fundamental to this optimisation problem is the distribution the investor employs to evaluate this expectation, the distribution used depends upon whether the investor believes bill returns are predictable. To ascertain the influence of predictability on allocation decisions a comparison between the allocations of an investor who ignores predictability, to one who takes it into account can be made, this is discussed in greater detail below.

The above investment strategy will be explored with $n=3,6$ and 12-month T-bill rates and $m=1$-month rate, where each of the three pairwise combinations of $n$ and $m$ will be examined. So over the investment horizon $H$, the investor will consider how to optimally allocate when faced with the following three portfolio choices:

(1) 1 -month vs 3 -month under $H=3,6,12,18,24$ months

(2) 1 -month vs 6 -month under $H=6,12,18,24$ months

(3) 1 -month vs 12 -month under $H=12,24$ months

In the case where $H=n$ there is uncertainty surrounding the future values of the short rates only and for $H>n$ there is uncertainty about the future long rates too. Each of (1), (2) and (3) are considered for the levels of risk aversion $A=2,5,10$, with $A=10$ being the highest level. Under these three portfolio combinations we consider how (i) the assumptions regarding predictability, (ii) whether the investor incorporates parameter uncertainty or not, (iii) her level of risk aversion and (iv) the length of the investment horizon, affect the way in which she allocates her portfolio. ${ }^{13}$

\subsection{The Predictive Density Function}

The approach taken to estimate the density function when parameter uncertainty is ignored and when it is incorporated will now be discussed. The form the density function $P\left(\mathbf{X}_{T+1, H} \mid \mathbf{X}_{T}\right)$ takes is determined by the types of uncertainty surrounding the forecasts, as well as the way in which the function is characterised and estimated. Studies including Kandel and Stambaugh (1996), Barberis and ASV estimate the density function using a fully Bayesian approach. We follow an alternative approach proposed by Garratt, Lee, Pesaran and Shin (2003 and 2006, henceforth GLPS) and GL, which takes a classical stance on the Bayesian approach to estimating the density function. This approach avoids the need for priors since approximations of certain probabilities of interest are made. We will now discuss the methods employed to estimating the predictive density, as proposed by GLPS and GL.

To evaluate each investment decision over the investment horizon the investor needs the probability density function of the forecast values of the $m$ - and $n$-month rates. Following GL $\mathbf{x}_{t}=\left(x_{1 t}, x_{2 t}, \ldots, x_{q t}\right)^{\prime}$ is a $q \times 1$ vector of $q$ variables (including at least the variables of interest i.e. $r_{t}^{(m)}$ and $\left.r_{t}^{(n)}\right)$, and $\mathbf{X}_{T}=\left(\mathbf{x}_{1}, \mathbf{x}_{2}, \ldots, \mathbf{x}_{T}\right)^{\prime}$ is a $q \times T$ vector containing the observations 1 to $T$ of the $q$ variables. The conditional probability density

\footnotetext{
${ }^{13}$ We assume that there are 4 weeks in a month and 13 weeks in 3 months. This assumption is made for ease of notation, in practice interest is accured daily and the length of time each investment is held for are equivalent.
} 
function $P\left(\mathbf{X}_{T+1, H} \mid \mathbf{X}_{T}\right)$ is required for the forecasts of the variables, this predictive density function gives the probability density function of the forecast values of the $q$ variables over the horizon $T+1$ to $T+H$, where $\mathbf{X}_{T+1, H}=\left(\mathbf{x}_{T+1}, \mathbf{x}_{T+2}, \ldots, \mathbf{x}_{T+H}\right)^{\prime}$ conditional on the observed values of the $q$ variables from 1 to $T$.

The investment problem that the investor is faced with depends on whether she considers the uncertainty surrounding the parameters. In the case where the investor ignores parameter uncertainty, she calculates the expectation over the distribution of returns conditional on the fixed parameter values $\widehat{\theta}$, so the predictive density is $P\left(\mathbf{X}_{T+1, H} \mid \mathbf{X}_{T}, \widehat{\theta}\right)$. The investor's problem to solve ignoring parameter uncertainty is:

$$
\max _{\omega}\left\{E_{T} v\left(W_{T+H}(\omega)\right)=\int v\left(W_{T+H}(\omega)\right) . P\left(\mathbf{X}_{T+1, H} \mid \mathbf{X}_{T}, \widehat{\theta}\right) d \mathbf{X}_{T+1, H}\right\}
$$

However, if the investor incorporates parameter uncertainty then the predictive density for the returns, which is conditional on the observed data only, is given by:

$$
P\left(\mathbf{X}_{T+1, H} \mid \mathbf{X}_{T}\right)=\int P\left(\mathbf{X}_{T+1, H} \mid \mathbf{X}_{T}, \widehat{\theta}\right) P\left(\theta \mid \mathbf{X}_{T}\right) d \theta
$$

The posterior probability of $\theta$, denoted $P\left(\theta \mid \mathbf{X}_{T}\right)$ gives the uncertainty surrounding the parameters given the observed data. So the investor's problem now is:

$$
\max _{\omega}\left\{E_{T} v\left(W_{T+H}(\omega)\right)=\int v\left(W_{T+H}(\omega)\right) \cdot P\left(\mathbf{X}_{T+1, H} \mid \mathbf{X}_{T}\right) d \mathbf{X}_{T+1, H}\right\}
$$

where the posterior density $P\left(\theta \mid \mathbf{X}_{T}\right)$, equation (8), is proportionate to the product $P(\theta) . P\left(\mathbf{X}_{T} \mid \theta\right)$, i.e. of the prior on $\theta$ and the likelihood function.

GLPS and GL suggest that the predictive density $P\left(\mathbf{X}_{T+1, H} \mid \mathbf{X}_{T}\right)$ can be estimated using Monte Carlo integration techniques if meaningful priors exist. However, in the circumstance where meaningful priors are difficult to obtain, they propose the use of approximations to the key probabilities needed to estimate the predictive density. They make the following assumption for the posterior probability of $\theta$ :

$$
\theta \mid \mathbf{X}_{T} \stackrel{\omega}{\sim} N\left(\widehat{\theta}_{T}, T^{-1} \widehat{\mathbf{V}}_{\theta}\right)
$$

where $\widehat{\theta}_{T}$ is the maximum likelihood estimate of the true parameter value of $\theta$ and $T^{-1} \widehat{\mathbf{V}}_{\theta}$ is the asymptotic covariance matrix of the estimated parameters $\widehat{\theta}_{T}$.

The forecasts are influenced by various uncertainties including stochastic, parameter and model uncertainty, here we consider both stochastic and parameter uncertainty. We abstract from model uncertainty, but do model interest rates under two different assumptions, first assuming returns are not predictable as given by the RW model, and second that they are predictable as given by the MVART model.

For these two models an estimate of the probability density function of the forecasts can be obtained using stochastic simulation techniques, where these simulations provide an estimate of the predictive densities $P\left(\mathbf{X}_{T+1, H} \mid \mathbf{X}_{T}, \widehat{\theta}\right)$ in the case where parameter uncertainty is ignored and $P\left(\mathbf{X}_{T+1, H} \mid \mathbf{X}_{T}\right)$ when it is considered. It is then possible to 
evaluate $E_{T}\left(v\left(W_{T+H}\right) \mid \Omega_{T}\right)$ for a range of portfolio weights $\omega$. In practice $v\left(W_{T+H}(\omega)\right)$ is computed $\widetilde{R}$ times for each value of $\omega$, then the mean across these $\widetilde{R}$ replications is calculated, from which the investor chooses the weight $\omega$ that maximises the expected utility $E_{T} v\left(W_{T+H}(\omega)\right)$. Here $\omega$ takes values $0,0.01, \ldots, 0.99,1$, where $\omega=0$ suggests that the investor should allocate all to n-month bills and $\omega=1$ suggests that all should be allocated to 1-month bills. Since the weight is between 0 and 1 we do not allow for short selling. Details of the estimation procedure, how the computations are carried out and the method by which the errors are calculated ${ }^{14}$ are provided in Appendix A.

Here we consider four possibilities for the distribution of future returns given by when the investor assumes no predictability compared to predictability, both when ignoring and then incorporating parameter uncertainty. From this, how the optimal allocations differ under the assumptions of predictability and parameter uncertainty can be observed.

\section{Modelling the UK Treasury Bill Rates}

\subsection{Interest Rate Data}

We employ data for UK Treasury Bills of maturities 1, 3, 6, 12 months over the period 1997 week 10 to 2007 week 19. Specifically, Wednesday observations of the nominal government spot rates, giving a total of 532 observations for each maturity, all yields ${ }^{15}$ are continuously compounded and annualised. ${ }^{16}$ These $n$-month nominal government spot interest rates refer to those applicable today on a $n$-month risk-free nominal loan and by definition this (the nominal government spot rate) is the yield to maturity of a nominal zero coupon bond. ${ }^{17}$

From Figure 1 the 1-, 3-, 6- and 12-month T-bill yields in general appear to decline until 2003, after which an upward trend is apparent, with average yields of $4.98 \%, 4.97 \%$, $4.96 \%$ and $4.99 \%$ for each rate respectively. Further, we find the yields are difference stationary, and the $(n, m)$ rate spreads between the $(3,1),(6,1)$ and the $(12,1)$ rates are stationary. Stationary spreads provide support for the EH, we find further support in the form of yields sharing a common stochastic trend with cointegrating vectors being $(1,-1)$ as implied by the EH. ${ }^{18}$

The two models are each estimated over the period 1997 week 10 to 2004 week 18 (374 observations) and then recursively at weekly intervals from 1997 week 10 to 2005

\footnotetext{
${ }^{14}$ The errors can be drawn using either parametric or non-parametric methods, see GLPS (2006, pp. 166-168). Here parametric methods are utilised, where the errors are assumed to be i.i.d.N (0, $\boldsymbol{\Sigma})$ serially uncorrelated white noise errors.

${ }^{15}$ We assume a buy-and-hold investor, so the investor requires the holding period returns for the bills in order to assess the investment strategies. Since the investor receives zero coupon payments, the yields used here reflect the total return from holding this asset, which are equivalent to the holding period returns. So what we refer to as returns/yields denoted $r_{t}^{(n)}$, are the holding period returns.

${ }^{16}$ We use official Bank of England estimated yield curve data because T-bill data is unavailable during some periods of our sample. However, little difference is observed when plotting the constructed data against the available T-bill data.

${ }^{17}$ See Bank of England data notes, refer to the Data Appendix for further details.

${ }^{18} \mathrm{We}$ only report the outcomes of the unit root and cointegration test results here, however full results are available on request.
} 
week 18 (427 observations), giving 54 recursions in total. For each recursion we generate $h$-step ahead out-of-sample forecasts ${ }^{19}$ for $h=1,2, \ldots, H, \ldots$ where the investment horizons $H=3,6,12,18$ and 24 months. So for the first recursion we forecast over the period 2004 week 19 to 2006 week 18 and for the last recursion 2005 week 19 to 2007 week 19. For each recursion the investor will use her generated forecasts to determine how to allocate her portfolio optimally. For each of the three portfolio choices, i.e. 1-month vs n-month $n=3,6,12$, under each $A$ and $H$, we will have 54 allocation decisions with which to compare the allocations and utility gains under each model, both without and with parameter uncertainty.

\subsection{Model Estimation}

Here we describe how we estimate the two models and present the estimated regression results for the first recursion over 1997 week 10 to 2004 week 18. Estimates of the RW model are given in Table 1. The optimal lag for the MVART model is chosen by estimating a set of $\operatorname{VAR}(p)$ models for $p=0,1, \ldots 12$ over 1997 week 10 to 2004 week 18, the optimal lag length is that which minimises the Schwarz Information lag selection criterion and based on this a MVART model of order 9 is estimated, Tables 2 and $3 .^{20}$ Comparing the two models, a gain in explanatory power for the 1-month return is observed when assuming returns are predictable and all coefficients are jointly significant at the $1 \%$ level under the MVART model. The diagnostics show evidence of serial correlation in the RW model, in contrast to the MVART model. Further, the nulls that the residuals are homoskedastic and normal are rejected under both models, which is not surprising given that we are using financial data. These results indicate gains in terms of explanatory power and having a model free of serial correlation when predictability is assumed.

\subsection{Statistical Forecast Evaluation}

A statistical evaluation of the out-of-sample forecast performance of the two models can be made using the root mean squared error (RMSE). The RMSEs of the 1-, 3-, 6- and 12-month return forecasts, for forecast horizons $H=1,3,6,12,18$ and 24 months for each model, both ignoring and incorporating parameter uncertainty are given in Table 4, and Table 5 reports the ratio of the RMSEs for each model to the benchmark model. The RW model when parameter uncertainty is ignored is taken as the benchmark, and a value of the ratio less than one indicates that the RMSE of the model is lower than that of the benchmark.

The RMSEs of the bill return forecasts indicate that only at $H=1$ for the 1-month return does the MVART model beat the benchmark. The RW and RWPU models, that make the strong 'no change' assumption, outperform the models that assume predictability at each horizon for the 3-, 6- and 12-month returns. The RMSEs of the RW models

\footnotetext{
${ }^{19}$ We denote the investment horizon $H$ in months because the T-bills are denoted as n-months to maturity. However, the data has a weekly frequency, so when we refer to the ' $h$-step' ahead forecasts each 'step' is a week.

${ }^{20}$ Estimates of each model for the first recursion only are provided to give an overall impression of the in-sample predictability. At the forecasting stage the models are estimated recursively.
} 
without and with parameter uncertainty are virtually the same, which is not surprising since we only estimate $\mu$; whereas small differences are observed between MVART and MVARTPU. In general, the differences observed in the RMSEs amongst the models are small. These results broadly correspond to those found in the interest rate and exchange rate forecasting literature, which reports that under statistical criteria sophisticated theory informed models are outperformed by a simple random walk.

From the ratios it is apparent that not only do the RW models outperform the MVART models $^{21}$, but the ratio of the MVART models to the benchmark increases with $H$, suggesting their forecasting ability deteriorates relative to the RW model with the investment horizon. Generally, the RMSEs increase up until $H=6$ before decreasing, implying that they are non-monotonic. That is, they do not increase with $H$ but instead oscillate in relative value, suggesting that both models are better at forecasting over longer horizons. This statistical evaluation does not provide an indication of how these models perform in an investment decision making context.

\section{Predictability \& Parameter Uncertainty Effects}

We now examine the implications for the optimal allocation when the investor assumes returns are not predictable compared to when predictability is assumed, in both cases parameter uncertainty is ignored and accounted for. In the case where parameters are assumed fixed the maximisation problem is given by equation (7) and under parameter uncertainty by equation (9).

The models are estimated first over 1997 week 10 to 2004 week 18, the optimal weights are then calculated from the forecasts generated from each estimated model. This is then repeated as we move forward by one week, re-calculating the expected utility to find the optimal weight for this new augmented sample. This is repeated for each recursion, such that we have results for 54 recursions over the total evaluation period 2004 week 19 to 2007 week 19. Figure 3 and Table 6 are based on the optimal allocation results averaged over the 54 recursions for a particular $A, H$, model and portfolio combination.

Figure 2 shows the expected utilities for each recursion from a rolling investment in the 1-month bill given by $E(U 1)$ and n-month given by $E(U n)$ for $n=3,6,12, A=2$ and $H=24$. We only present the plots for $A=2$ and $H=24$ for illustrative purposes, the results under $A=5,10$ and $H=6,12,18$ are not significantly different. It can be seen that the computed expected utilities, although of similar magnitude, are different under each model. Further, there are differences in the way the expected utilities change over the recursions under the RW and MVART models, these differences will be reflected in how the investor ultimately allocates.

Figures 3 provides an illustration of the link between the expected utilities computed by the investor and the optimal allocation. It depicts the optimal allocation to the 1month, $100 \omega \%$, given the difference in $E(U)$ between the 'all in the 3-month' and 'all

\footnotetext{
${ }^{21}$ The 'RW models' and the 'MVART models' refer to those estimated without and with parameter uncertainty. When analysing the results later we compare RW with MVART first ignoring parameter uncertainty and then when it is incorporated.
} 
in the 1-month' investments, for each investment horizon, for $A=2$ under the MVART model ignoring parameter uncertainty. It can be seen that when the difference is positive, where we expect to gain a higher utility from investing 'all in the 3-month' than 'all in the 1-month', the investor allocates her entire initial wealth in 3-month T-Bills, and vice versa when the difference is negative. ${ }^{22}$

The impact of the various effects upon the allocations is summarised in Table 6. Here under each portfolio combination for a given $A, H$ and model the table gives as a percentage the number of times out of the 54 recursions the investor allocates everything to the 1 month bill, i.e. $\omega=1$. The results are presented this way, firstly, because nearly all the allocation results suggest an optimal weight of $\omega=0$ or 1 . This implying that the investor, given the aim is to maximise expected utility, invests everything either in 1month or $n$-month bills depending on which yields the higher expected utility, and not a mix of the two bills considered. Secondly, using these percentages we can see how the allocations differ under varying degrees of risk aversion, investment horizons, assumptions of predictability and the inclusion of parameter uncertainty.

The allocations vary by 0 to $8 \%$ amongst the three levels of risk aversion, $A$, considered. ${ }^{23}$ These small differences in allocation are arguably not surprising given that the assets considered here belong to the same asset class, only differ in their term to maturity and are positively correlated. So even though the investor may be highly risk averse, the opportunity for the investor to diversify out the risk here is small because the risk is non-diversifiable.

Now comparing the allocations for different investment horizons for a particular 1month vs $n$-month portfolio combination and model, the allocation to the 1 -month generally increases with the investment horizon, where the increases are larger under predictability. This suggests that if the investor assumes predictability, then the allocations are more sensitive to the investment horizon.

If the returns are modelled as being non-stationary, the variance of the returns continue to grow linearly with $H$. However, if the yields are modelled as stationary the variance grows less than linearly and in the long run converges to some long-run value. ${ }^{24}$ How the variance evolves will be translated through to the variance of the cumulative returns, which will determine how risky the asset appears in the long run compared to the short run, and thus how the investor's allocation will differ with the investment horizon. Here the yields are found to be and thus modelled as non-stationary under both the RW and MVART models. Hence both the RW and MVART models' variances will evolve in the same way, i.e. faster than linearly with $H$, suggesting that the bills appear riskier in the longer run than the shorter horizons for both models. Since it is not possible to rank

\footnotetext{
${ }^{22}$ We only present the plots for $A=2$ because a significant difference in allocations between the different $A$ is not observed. Further, we only show the plots under the MVART model for the 1-month vs 3-month strategy to provide a general impression of the link between the expected utilities the investor calculates and how she eventually allocates between the two bills.

${ }^{23}$ The results were not significantly different when this exercise was carried out with extreme levels of risk aversion i.e. $A=20,50,100$.

${ }^{24} \mathrm{An}$ appendix discussing the mean and variance of returns when the returns are modelled as nonstationary, in comparison to when they are treated as stationary is available on request.
} 
the variances under each model a priori, we later discuss how the actual variances of the forecasts evolve with $H$ here under each model using our computed RMSEs.

\subsection{Effect of Predictability}

We now examine the effect of predictability ignoring parameter uncertainty on the optimal allocation. When comparing the RW with the MVART model the investor moves from assuming no predictability to predictability of returns. Under predictability if the investor is better able to capture and explain the yields, i.e. in-sample $\bar{R}^{2}$ is higher, then assuming that the relationship remains stable over the forecast horizon, we would expect the MVART model to produce more accurate forecasts. Thus the variance of the forecasts under the MVART would be lower than that under the RW, and hence the asset would look less risky under the MVART.

Moving from the RW model to the MVART model there is a gain (in-sample) in explanatory power with the $\bar{R}^{2}$ for $\Delta r_{t}^{(1)}$ increasing from $0 \%$ to $27 \%$. Although only $\Delta r_{t}^{(1)}$ is directly comparable under both models, it is reasonable to expect that all the $n$-month bills will gain when moving from the RW to the MVART model in terms of explanatory power $^{25}$, such that it applies to all the returns that as they become more predictable they become more attractive to the investor.

However, this gain in in-sample predictability is not translated into an out-of-sample gain, as the RMSEs of the MVART model are higher than those of the RW. However, GL note "...as shown in Clements and Hendry (2005), using RMSE as a criterion penalises models for including variables with low associated t-values even if the model is misspecified by their exclusion", so the poor performance of the MVART model according to the RMSE criterion may be largely due to the fact that it is heavily parameterised in comparison to the RW model.

The difference in allocations between the RW and MVART models varies from 8 to $58 \%$. Under 1 -month vs 3 -month, for all $H$, the MVART models allocate more to the 1 -month. However, under the 1 -month vs 6 -month and the 1-month vs 12 -month for each $H$, it is the RW models that allocate more to the 1-month. For each portfolio combination (1-month vs $n$-month, for $n=3,6$ and 12-month bills) both of the assets will go from being 'not predictable' as determined by the random walk, to being 'predictable' as described by the MVART, so how the allocation differs under the RW to that under the MVART will depend on which of the two bills gains more from the assumption of predictability.

Generally, large differences are observed between the allocations of the RW models and MVART models, suggesting that the investor who assumes that returns are not predictable will allocate differently to one who assumes that they are predictable. Thus the assumptions made regarding predictability are important in determining how the investor allocates.

\footnotetext{
${ }^{25}$ Regression results showing that past changes and spreads have explanatory power for $\Delta r_{t}^{(n)}$ for $n=$ 1, 3,6 and 12 months are not included here, but are available upon request.
} 


\subsection{Effect of Parameter Uncertainty}

Looking now to the effect of parameter uncertainty, incorporating parameter uncertainty increases the variance of the forecast returns at all $H$, so the asset looks riskier relative to when it was modelled ignoring parameter uncertainty. If all the assets are affected by this additional form of uncertainty, how the allocation changes when parameter uncertainty is incorporated to when it is ignored, under a given model, will be determined by which asset's variance has increased the most.

Comparing the allocations without and with parameter uncertainty for both the RW and the MVART models in turn allows the impact of parameter uncertainty to be isolated. The impact on allocation varies by 0 to $21 \%$ under the RW model. In the 1 -month vs 3 -month portfolio combination, at all $H$ the allocation changes by 0 to $2 \%$; 1 -month vs 6 month by 0 to $6 \%$; 1 -month vs 12 -month $H=12$ by 0 to $2 \%$ and up to $21 \%$ for $H=24$. In most cases the allocation to the 1-month increases under parameter uncertainty, suggesting that the 1-month looks comparatively less riskier than the n-month when parameter uncertainty is incorporated.

Under the MVART model parameter uncertainty has more of an impact, where the change in the allocation ranges from 0 to $17 \%$. For each of the portfolio combinations, for all $H$, in the 1 -month vs 3 -month the allocation changes by 0 to $6 \%$; 1 -month vs 6 -month by 7 to $17 \%$ and no change is observed in the 1-month vs 12-month. Mostly the allocation to the 1-month decreases under parameter uncertainty, implying that under the MVART model with parameter uncertainty the 1-month looks riskier.

To help explain the optimal allocations observed we can consider how the variances about the distribution of future predicted returns evolves over the forecast horizon. ${ }^{26}$ Here it is reasonable to suppose that the RMSEs and the variances are closely related ${ }^{27}$, allowing us to use the RMSEs as an indication of how the variances of the forecasts evolve. Recall Tables 4 and 5, the non-monotonic RMSEs imply that the variances of the forecasts are also non-monotonic ${ }^{28}$, they increase up until $H=6,12$ months and then decline.

Since the variance about the forecasts contracts and expands with $H$, the asset will appear more risky at some horizons than at others. Further, the variances of the different returns oscillate at different rates, otherwise the RMSE for each return would be equal. This indicates that some $n$-month returns have a greater variance about their distribution of forecasts than others, so at some horizons the 1-month bill will appear more risky than the $n$-month and at others less. Under the RW models a clear ranking emerges with the 1-month having the largest variance and the 12-month the smallest, for all $H$. Under the

\footnotetext{
${ }^{26}$ Given that the bill returns are non-stationary in levels, then the variances will grow faster than linearly with $H$ under both the RW and MVART models.

${ }^{27}$ The RMSE measures the dispersion around the actual value of a variable, whereas the variance measures the dispersion about the mean of the distribution. If the distribution is unbiased then the mean of the distribution equals the actual value, in which case the RMSE equals the variance of the forecast.

${ }^{28}$ Non-monotonic variances may not be so surprising as Hall and Hendry (1988, pp. 256-7) highlight "Hendry (1984) has demonstrated that the standard error need not increase monotonically, as there is a term in the formulae for the model standard error which reaches a maximum and which then may decline.", further Hall and Hendry suggest that if this non-monotonicity (in the model standard error) is stronger than the rest of the formulae, then the total standard error will behave in this non-monotonic way.
} 
MVART models the variances are not only bigger for each bill and $H$, but seem to oscillate more, with the 1-month looking less risky than the $n$-month over the shorter horizons and more risky over the longer horizons.

This non-monotonicity combined with the fact that the variances of the returns expand and contract at different rates could provide an explanation for the optimal allocations observed here. In that, when computing expectations of $v\left(W_{T+H}(\omega)\right)$, due to the nonlinear nature of $W_{T+H}$ the investor requires the variances and the covariances of the forecast returns at each step ahead as well as their means. So how the variances of the forecasts differ for each $n$-month bill over $H$, together with the assumptions regarding predictability and parameter uncertainty, will influence expected utility because of the way it is calculated and hence the ultimate optimal allocation.

\section{Economic Value of Predictability}

It is clear from the results that the allocations are sensitive to the assumptions made regarding predictability, whether parameter uncertainty is incorporated and the investment horizon. In this investigation we also seek to ascertain if there is economic value to interest rate predictability. The RMSE provides a statistical measure of forecast accuracy, we now will assess forecast performance by considering the economic value of the forecasts to the investor. An economic evaluation of the forecast performance of each model is reported in Table 7 under each portfolio combination for $A=2$ and each $H$. Results are reported for $A=2$ only because those for $A=5$ and 10 are not considerably different. We compute the end-of-period wealth ${ }^{29}$ that the risk averse investor would have achieved over 2004 week 19 to 2007 week 19, had she allocated her portfolio as suggested by the optimal weights. Where the optimal weight $\omega$ is that calculated by solving the utility maximisation problem ${ }^{30}$, these realised wealths are averaged over 54 recursions and then ranked in descending order so the performance of each model can be compared.

Apart from the RW and MVART models described above, under which parameter uncertainty is both ignored and incorporated to derive the optimal allocations, we introduce two passive 'lazy' strategies. Here the investor makes no attempt to model or predict the returns, but instead either invests (1) all in 1-month bills (A1) or (2) all in n-month bills (An) for $n=3,6$ or 12 .

The top position is mostly occupied by the lazy 'all in 1-month' strategy, with the 'all in n-month' strategy coming last. This is not surprising given that during a large part of the forecast horizon 2004 week 19 to 2007 week 19, over which this evaluation of the models is made, the 1-month return was higher than the others, Figure 1. Looking to positions 2 to 5 , under the 1 -month vs 3 -month the RW models perform well at $H=3,6$ and the MVART models at $H=12,18,24$. Under 1-month vs 6 -month and 1-month vs 12-month the success of the RW models is apparent at all $A$ and $H$.

\footnotetext{
${ }^{29}$ We follow ASV and GL in our measure of economic value being based on wealth.

${ }^{30}$ The forecasts produced by each model are used to determine the optimal weight. These weights are then combined with actual/realised returns to give the realised end-of-horizon wealth.
} 
We have considered two different forecast evaluation criteria, the RMSE which provides a statistical measure and the realised wealths which is an economic value measure of forecast accuracy. When comparing the results under the two criteria, under the 1-month vs 3-month the RW models outperform the MVART models at all $H$ when considering the RMSEs, whereas the MVART models achieve a higher realised wealth at $H=12,18,24$ under the economic value measure. So the conclusions drawn under each criterion do not entirely correspond. Under the 1-month vs 6 -month and 1-month vs 12 -month both the statistical and the economic value criteria do correspond, to find that the RW models perform best at all $H$.

Further, from the RMSE ratios in Table 5, the performance of the MVART models relative to the benchmark deteriorates as $H$ increases. In which case, we would also expect the difference between the realised wealths of the two models to increase as $H$ increases. But the differences in the realised wealths between the RW and MVART models are small and the ratios of the realised wealths to the benchmark, Table 8 , are quite constant over $H$.

So the RMSEs suggest that the forecasting errors of the MVART models are larger than those of the RW models. But when considering realised wealths a huge difference is not observed, with this economic value measure not exhibiting such an obvious difference between assumptions of no predictability and predictability.

We ignore transactions costs in this exercise, but appreciate that the transactions costs of a rolling investment in $m$-period bills will be higher than that of an investment in a $n$-period long bond. From the realised wealths in Table 7, the differences in the realised wealths between the two strategies are very small, with any gain from adopting a rolling strategy likely to be eradicated with the inclusion of transactions costs.

\section{Conclusion}

Previous studies find that by using an alternative assessment criterion that considers the economic value of the forecasts, in comparison to conventional statistical methods can yield support for theory informed models. This highlights the importance of judging forecasts in the decision making context for which they are intended.

In this investigation we examine how the optimal allocations of a utility maximising investor are affected by the assumptions she makes regarding the predictability of returns and parameter uncertainty. If the investor believes that returns are not predictable she uses a random walk with drift model in her decision making. Alternatively, if she believes they are predictable she uses the fundamentals informed MVART model, that embeds the cointegration relations implied by the EH. Further, we evaluate the economic value of the out-of-sample forecasts of bill returns generated under these two models.

The effect of assuming predictability on the optimal allocation is considerable, where the optimal weights under predictability are in some cases greatly different to those under no predictability. The effect of parameter uncertainty is small over the investment horizon considered here. 
Under the statistical evaluation criterion the RW models outperform the MVART models at almost all horizons when forecasting bond returns, even though evidence of misspecification at the estimation stage is found under the RW model. When an economic value approach is used, we find some evidence to suggest that an investor seeking to optimally allocate her wealth between 1-month and n-month UK T-bills is better off, in terms of higher end-of-horizon wealth, by assuming predictability than an investor who assumes no predictability.

From Clements and Hendry (2005) as quoted in GL, the RMSE criterion penalises heavily parameterised models. Here, this could be exaggerating the superior performance of the RW model relative to the MVART under this criterion. Although the realised wealths imply that in some cases there are no gains from assuming predictability, the realised wealths of the two models are of the same magnitude and their ratios are very close to one. What can be deduced from these results is that the performance of the MVART model under the economic value criterion is not as poor as the RMSEs would suggest. This evidence of disparity between the results obtained under the two criteria suggests that the results are sensitive to the criterion used.

In conclusion, our results highlight the importance of evaluating the forecasts using an appropriate criterion. Here the investor is concerned with optimally allocating her portfolio, so it is necessary to incorporate the investor's feelings about risk and to consider the distribution about the predicted returns in the decision making and forecast evaluation process. In which case, the RMSE criterion seems somewhat inadequate for this purpose compared to the decision-based measure, which considers the objectives of the forecast user. In the context of investment decision making, we find some evidence of economic value to interest rate predictability, such that the investor may gain from assuming predictability. 


\section{Bibliography}

1. Abhyankar A, Sarno L, Valente G. 2005. Exchange rates and fundamentals: evidence on the economic value of predictability. Journal of International Economics 66: $325-348$.

2. Avramov D. 2002. Stock return predictability and model uncertainty. Journal of Financial Economics 64: 423-458.

3. Barberis N. 2000. Investing for the Long Run when Returns Are Predictable. The Journal of Finance 55: 225-264.

4. Boudry W, Gray P. 2003. Assessing the Economic Significance of Return Predictability: A Research Note. Journal of Business Finance \& Accounting 30: 1305-1326.

5. Campbell JY, Shiller RJ. 1991. Yield Spreads and Interest Rate Movements: A Bird's Eye View. The Review of Economic Studies 58, Special Issue: The Econometrics of Financial Markets, 495-514.

6. Cenesizoglu T, Timmermann A. 2012. Do return prediction models add economic value? Journal of Banking and Finance 36: 2974-2987.

7. Clements MP, Hendry DF. 2005. Evaluating a Model by Forecast Performance. Oxford Bulletin of Economics \& Statistics 67: 931-956.

8. Cuthbertson K. 1996. The Expectations Hypothesis of the Term Structure: The UK Interbank Market. The Economic Journal 106: 578-592.

9. Cuthbertson K, Nitzsche D. 2004. Quantitative Financial Economics: Stocks, Bonds and Foreign Exchange. John Wiley \& Sons.

10. Cuthbertson K, Hayes S, Nitzsche D. 2000. Are German money market rates well behaved? Journal of Economic Dynamics and Control 24: 347-360.

11. Cuthbertson K, Hayes S, Nitzsche D. 1996. The Behaviour of Certificate of Deposit Rates in the UK. Oxford Economic Papers 48: 397-414.

12. Della Corte P, Sarno L, Thornton DL. 2008. The expectation hypothesis of the term structure of very short-term rates: Statistical tests and economic value. Journal of Financial Economics 89: 158-174.

13. De Pooter M, Ravazzolo F, van Dijk D. 2007. Predicting the Term Structure of Interest Rates, Incorporating parameter uncertainty, model uncertainty and macroeconomic information. Working Paper, Econometric Institute and Tinbergen Institute, Erasmus University Rotterdam.

14. Diebold FX, Li C. 2006. Forecasting the term structure of government bond yields. Journal of Econometrics 130: 337-364. 
15. Fama EF. 1990. Term-structure forecasts of interest rates, inflation and real returns. Journal of Monetary Economics 25: 59-76.

16. Fauvel Y, Paquet A, Zimmermann C. 1999. A Survey on Interest Rate Forecasting. CREFE Working Paper 87, University of Quebec.

17. Garratt A, Lee K. 2009. Investing Under Model Uncertainty: Decision Based Evaluation of Exchange Rate Forecasts in the US, UK and Japan. Journal of International Money and Finance 29: 403-422.

18. Fuertes A, Olmo J. 2013. Optimally harnessing inter-day and intra-day information for daily value-at-risk prediction. International Journal of Forecasting 29: 28-42.

19. Garratt A, Lee K, Pesaran MH, Shin Y. 2006. Global and National Macroeconometric Modelling: A Long-Run Structural Approach. Oxford University Press, Oxford.

20. Gosell TF, Kolb RW. 1997. Accuracy of International Interest Rate Forecasts. The Financial Review 32: 431-448.

21. Granger CW, Pesaran M. 2000. Economic and Statistical Measures of Forecast Accuracy. Journal of Forecasting 19: 537-560.

22. Guidolin M, Timmermann A. 2009. Forecasts of US short-term interest rates: A flexible forecast combination approach. Journal of Econometrics 150: 297-311.

23. Hall SG, Henry SGB. 1988. Macroeconomic Modelling contributions to economic analysis. North-Holland Publishing Company.

24. Hafer RW, Hein SE, MacDonald SS. 1992. Market and survey forecasts of the three-month treasury-bill rate. Journal of Business 65: 123-138.

25. Han Y. 2010. On the Economic Value of Return Predictability. Annals of Economics and Finance 11: 1-33.

26. Kandel S, Stambaugh RF. 1996. On the Predictability of Stock Returns: An AssetAllocation Perspective. The Journal of Finance 51: 385-424.

27. Klein RW, Bawa VS. 1976. The effect of estimation risk on optimal portfolio choice. Journal of Financial Economics 3: 215-231.

28. Leitch G, Tanner JE. 1991. Economic forecast evaluation: Profits versus the conventional error measures. American Economic Review 81: 580-590.

29. Longstaff FA. 2000. The term structure of very short-term rates: New evidence for the expectations hypothesis. Journal of Financial Economics 58: 397-415.

30. Marquering W, Verbeek M. 2004. The economic value of predicting stock index returns and volatility. Journal of Financial and Quantitative Analysis 39: 407-429. 
31. Merton RC. 1969. Lifetime Portfolio Selection Under Uncertainty: the ContinuousTime Case. Review of Economics \&3 Statistics 51: 247-257.

32. Pesaran MH, Skouras S. 2002. Decision Based Methods for Forecast Evaluation. In (eds) Clements MP, Hendry DF. A Companion to Economic Forecasting. Blackwell Publishers, Chapter 11, 241-267.

33. Pesaran MH, Timmermann A. 1995. Predictability of Stock Returns: Robustness and Economic Significance. Journal of Finance 50: 1201-1228.

34. Samuelson PA. 1969. Lifetime Portfolio Selection by Dynamic Stochastic Programming. Review of Economics \&3 Statistics 51: 239-246.

35. Sarno L, Thornton D, Valente G. 2007. The Empirical Failure of the Expectations Hypothesis of the Term Structure of Bond Yields. Journal of Financial 86 Quantitative Analysis 42: 81-100.

36. Taylor MP. 1992. Modelling the Yield Curve. The Economic Journal 102: 524-537.

37. Thornton DL, Valente G. 2012. Out-of-Sample Predictions of Bond Excess Returns and Forward Rates: An Asset Allocation Perspective. The Review of Financial Studies 25: 3141-3168.

38. West K, Edison H, Cho D. 1993. A utility-based comparison of some models of exchange rate volatility. Journal of International Economics 35: 23-45.

39. Xia Y. 2001. Learning about Predictability: The Effects of Parameter Uncertainty on Dynamic Asset Allocation. Journal of Finance 56: 205-246. 


\section{Data Appendix}

Here we provide details of the data used.

- Source: Bank of England (BoE)

http://www.bankofengland.co.uk/statistics/yieldcurve/archive.htm

- Definition: Nominal government n-month spot interest rate obtained from 'UK Nominal Spot Curve' at the short end. The curve is estimated using gilt prices and General Collateral (GC) repos rates. We use Wednesday observations from the reported daily data on the annualised and continuously compounded 1-, 3-, 6- and 12 -month rates.

- Notes on the BoE UK yield curves provides further details:

$$
\begin{aligned}
& \text { http://www.bankofengland.co.uk/statistics/yieldcurve/ } \\
& \text { notes\%20on\%20the\%20bofe\%20uk\%20yield\%20curvesV2.pdf }
\end{aligned}
$$

\section{Appendix A: Computing Density Forecasts based on the VAR model}

Here we describe how an estimate of the probability density function of the forecasts can be obtained through stochastic simulation techniques. We follow the discussion provided in GLPS and GL. The estimation procedure is discussed firstly for given values of the parameters and then by taking parameter uncertainty into account.

From equation (3), the maximum likelihood estimates of the model parameters are denoted $\widehat{\theta}=\left(\widehat{\mu}, \hat{\mathbf{B}}_{i}, \hat{\boldsymbol{\Sigma}}\right)$, for $i=1$ to $p$. In the absence of parameter uncertainty the investor assumes there is no uncertainty about the model parameters and they are fixed at the estimated values. The model is iterated forward to produce the point estimates of the $h$-step ahead forecasts, conditional on the observed data $\mathbf{X}_{T}$ and the estimated parameter values $\widehat{\theta}$ :

$$
\hat{\mathbf{x}}_{T+h}=\widehat{\mu}+\sum_{i=1}^{p} \hat{\mathbf{B}}_{i} \hat{\mathbf{x}}_{T+h-i}
$$

for $h=1,2, \ldots, H, \ldots$ Using the initial values of the variables $\mathbf{x}_{T,} \mathbf{x}_{T-1, \ldots}, \mathbf{x}_{T-p+1}$, these forecasts are produced recursively.

First considering stochastic uncertainty only, the forecast values of the variables $\mathbf{x}_{T+h}$ can be computed using stochastic simulations, providing an estimate of $P\left(\mathbf{X}_{T+1, H} \mid \mathbf{X}_{T}, \widehat{\theta}\right)$ from:

$$
\mathbf{x}_{T+h}^{(\widetilde{r})}=\widehat{\mu}+\sum_{i=1}^{p} \hat{\mathbf{B}}_{i} \hat{\mathbf{x}}_{T+h-i}+\gamma_{T+h}^{(\widetilde{r})}
$$

where $\mathbf{x}_{T+h}$ is the $h$-step ahead forecast. Given that $H$ is the end of the investment period, the investor is concerned with forecasts from $h=1$ to $H$. Further, let $\widetilde{R}$ denote the total number of replications of the above simulation, $\widetilde{r}=1$ to $\widetilde{R}$ and gives the $\widetilde{r}^{t h}$ replication. Furthermore, for current and past values of $\mathbf{x}$ the actual values are used such that $\mathbf{x}_{T+h-i}^{(\widetilde{r})}=\mathbf{x}_{T+h-i}$ for each replication.

To generate forecasts in the presence of parameter uncertainty the monte carlo procedure is used. First, the (in-sample) past values of $\mathbf{x}_{t}$ are simulated $\widetilde{H}$ times, $t=1,2, \ldots, T$, 
denoted $\mathbf{x}_{t}^{(\widetilde{h})}, \widetilde{h}=1,2, \ldots, \widetilde{H} \cdot{ }^{31}$, as follows:

$$
\mathbf{x}_{t}^{(\widetilde{h})}=\widehat{\mu}+\sum_{i=1}^{p} \hat{\mathbf{B}}_{i} \hat{\mathbf{x}}_{t-i}^{(\widetilde{h})}+\gamma_{t}^{(\widetilde{h})}
$$

where the actual realised values of $\mathbf{x}_{t}, \mathbf{x}_{t-1}, \ldots, \mathbf{x}_{t-p}$ are used for initial values, together with the estimated model parameters $\widehat{\theta}$ obtained using the actual observed data. With the $\widetilde{H}$ simulated 'histories' for $\mathbf{x}_{t}$ i.e. $\mathbf{x}_{1}^{(\widetilde{h})}, \mathbf{x}_{2}^{(\widetilde{h})}, \ldots, \mathbf{x}_{T}^{(\widetilde{h})}$, now estimate the $\operatorname{VAR}(p)$ model given by equation (3) $\widetilde{H}$ times, yielding $\widetilde{H}$ sets of ML parameter estimates $\widehat{\mu}^{(\widetilde{h})}, \hat{\mathbf{B}}_{i}^{(\widetilde{h})}, \gamma_{t}^{(\widetilde{h})}$ and $\boldsymbol{\Sigma}^{(\widetilde{h})}$. For each monte carlo replication compute $h$-step ahead point forecasts of $\mathbf{x}_{T}$, where $\widetilde{R}$ replications of these forecasts are generated by:

$$
\mathbf{x}_{T+h}^{(\widetilde{h}, \widetilde{r})}=\widehat{\mu}^{(\widetilde{h})}+\sum_{i=1}^{p} \hat{\mathbf{B}}_{i}^{(\widetilde{h})} \hat{\mathbf{x}}_{T+h-i}^{(\widetilde{h}, \widetilde{r})}+\gamma_{T+h}^{(\widetilde{h}, \widetilde{r})}
$$

for $h=1,2, \ldots, H ; \widetilde{r}=1,2, \ldots, \widetilde{R}$ and $\widetilde{h}=1,2, \ldots, \widetilde{H}$, noting that $h$ refers to the horizon and $\widetilde{h}$ to the number of histories generated and $S=(\widetilde{H}+1) \cdot \widetilde{R}=$ total number of simulations.

The $\gamma_{T+h}^{(\widetilde{r})}, \gamma_{t}^{(\widetilde{h})}$ and $\gamma_{T+h}^{(\widetilde{h}, \widetilde{r})}$ values can be drawn using either parametric or non-parametric methods (see GLPS (2006, pp. 166-168 and Cuthbertson and Nitzsche (2004, pp. 648) for further details), here parametric methods are utilised where the errors are assumed to be i.i.dN $(0, \boldsymbol{\Sigma})$ serially uncorrelated white noise errors.

Given that the simulations provide an estimate of the predictive densities $P\left(\mathbf{X}_{T+1, H} \mid \mathbf{X}_{T}, \hat{\theta}\right)$ when ignoring parameter uncertainty and $P\left(\mathbf{X}_{T+1, H} \mid \mathbf{X}_{T}\right)$ when it is considered, it is possible to evaluate $E_{T}\left(v\left(W_{T+H}\right) \mid \Omega_{T}\right)$ for a range of portfolio weights $\omega . \quad v\left(W_{T+H}(\omega)\right)$ is computed $\widetilde{R}$ times for each $\omega$, then the mean across these $\widetilde{R}$ replications is calculated, from which the $\omega$ that maximises the expected utility $E_{T} v\left(W_{T+H}(\omega)\right)$ is chosen.

The predictive densities here are computed using the methods described in GL and GLPS, all of the steps below are conducted for both the RW and MVART models.

Considering stochastic uncertainty only: $P\left(\mathbf{X}_{T+1, H} \mid \mathbf{X}_{T}, \widehat{\theta}\right)$

Using the estimated model parameters $\widehat{\theta}$, forecasts of the returns are generated $r_{T+h}^{(\widetilde{r})}$ for $h=1, \ldots, H$ and $\widetilde{r}=1, \ldots, \widetilde{R}$. Here $\widetilde{R}=50,000$. From these forecasts values of $W_{T+H}^{(\widetilde{r}, \omega)}$ can be calculated for each replication, where $\omega=0, \ldots, 1$ increasing in steps of 0.01 . So for each value of $H$ we have $\widetilde{R} \times 101$ values of $W_{T+H}^{(\widetilde{r}, \omega)}$, here $H=3,6,12,18$ and 24 months. Further, these wealths are used to calculate utility as given by the CRRA definition, $v_{T+H}^{(\widetilde{r}, \omega, A)}$ where $A=2,5$ and 10 . For the given values of $\omega, A$ and $H$ the expected utility is given by averaging across the replications as follows:

$$
E_{T} v\left(W_{T+H}\right)=\frac{1}{\widetilde{R}} \sum_{\widetilde{r}=1}^{\widetilde{R}} v_{T+H}^{(\widetilde{r}, \omega, A)}
$$

Hence for a given investment horizon $H$ and level of risk $A$, the investor selects that

\footnotetext{
${ }^{31}$ Note that ' $\widetilde{r}$ ' refers to the number of 'futures'generated in the simulation, ' $r$ ' refers to the asset return, ' $h$ ' refers to the 'histories' generated and ' $h$ ' refers to the step ahead forecasts.
} 
portfolio weight which maximises expected utility.

Considering stochastic and parameter uncertainty: $P\left(\mathbf{X}_{T+1, H} \mid \mathbf{X}_{T}\right)$

Using the estimated model parameters $\widehat{\theta}$, in-sample values of $\mathbf{x}_{T}$ are simulated $\widetilde{H}$ times, where $t=1, \ldots, T$ and $\widetilde{h}=1, \ldots, \widetilde{H}$, here $\widetilde{R}=1000$ and $\widetilde{H}=2000$. Using each of these $\widetilde{H}$ 'histories' of $\mathbf{x}_{T}$ estimate the model, this yields $\widetilde{H}$ sets of parameter estimates $\widehat{\theta}^{(\widetilde{h})}$. For each history compute $\widetilde{R}$ replications of the $h$-step ahead point forecasts of $\mathbf{x}_{T}$, where $\widetilde{r}=1, \ldots, \widetilde{R}$. Repeat the above steps from the stochastic uncertainty only method above for each history and its corresponding set of $\widetilde{R}$ simulated futures. Such that $\widetilde{H}$ sets of $E_{T} v\left(W_{T+H}\right)$ are calculated for given values of $\omega, A$ and $H$, the investor selects the portfolio weight that maximises $E_{T} v\left(W_{T+H}\right)$ for a given $H$ and $A$, for each history $\widetilde{H}$. 
Figure 1: Nominal Spot Yields 1997 to 2007

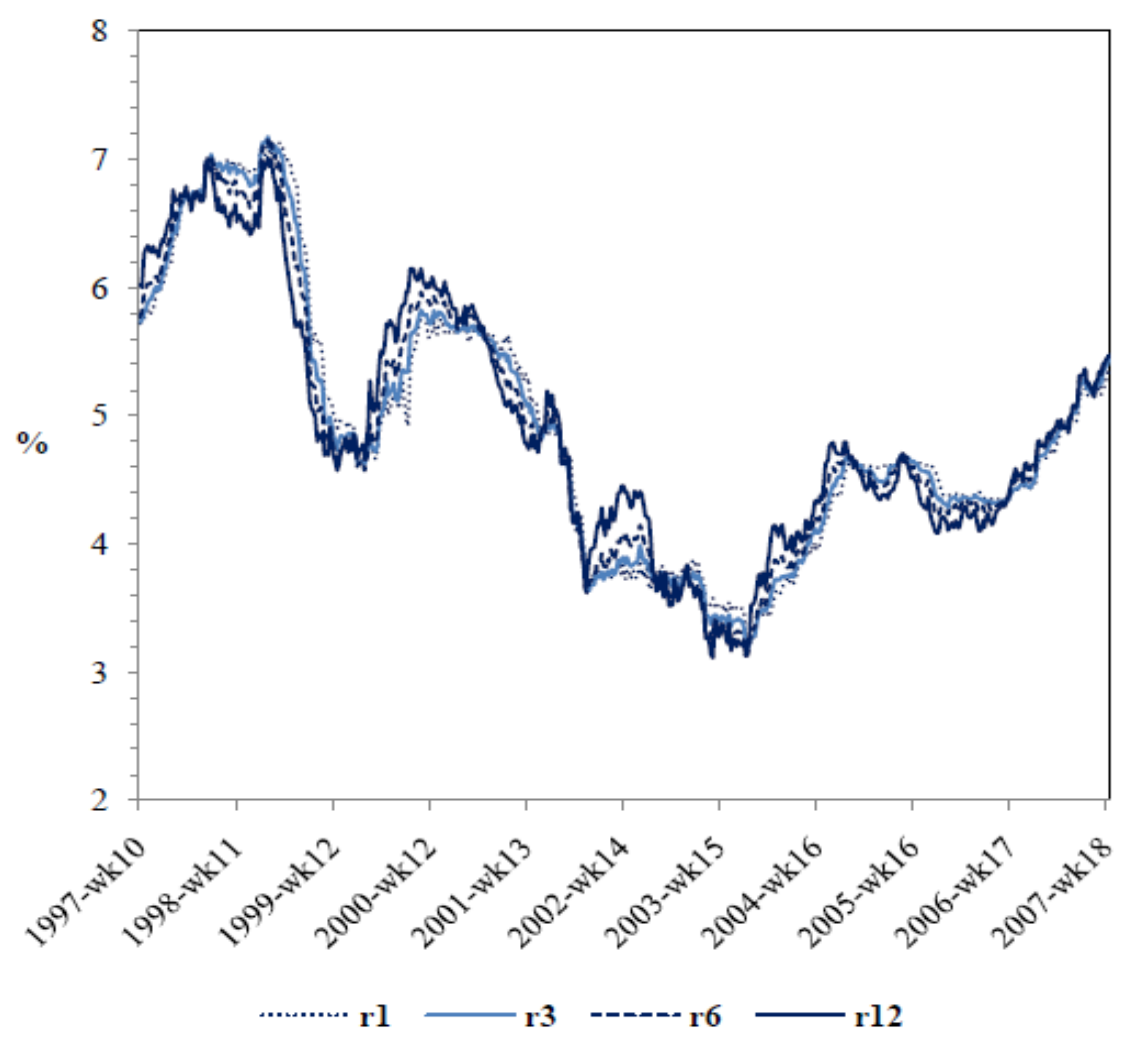


Figure 2: Expected Utility under RW and MVART Models, for $\mathrm{H}=24$ and $\mathrm{A}=2$
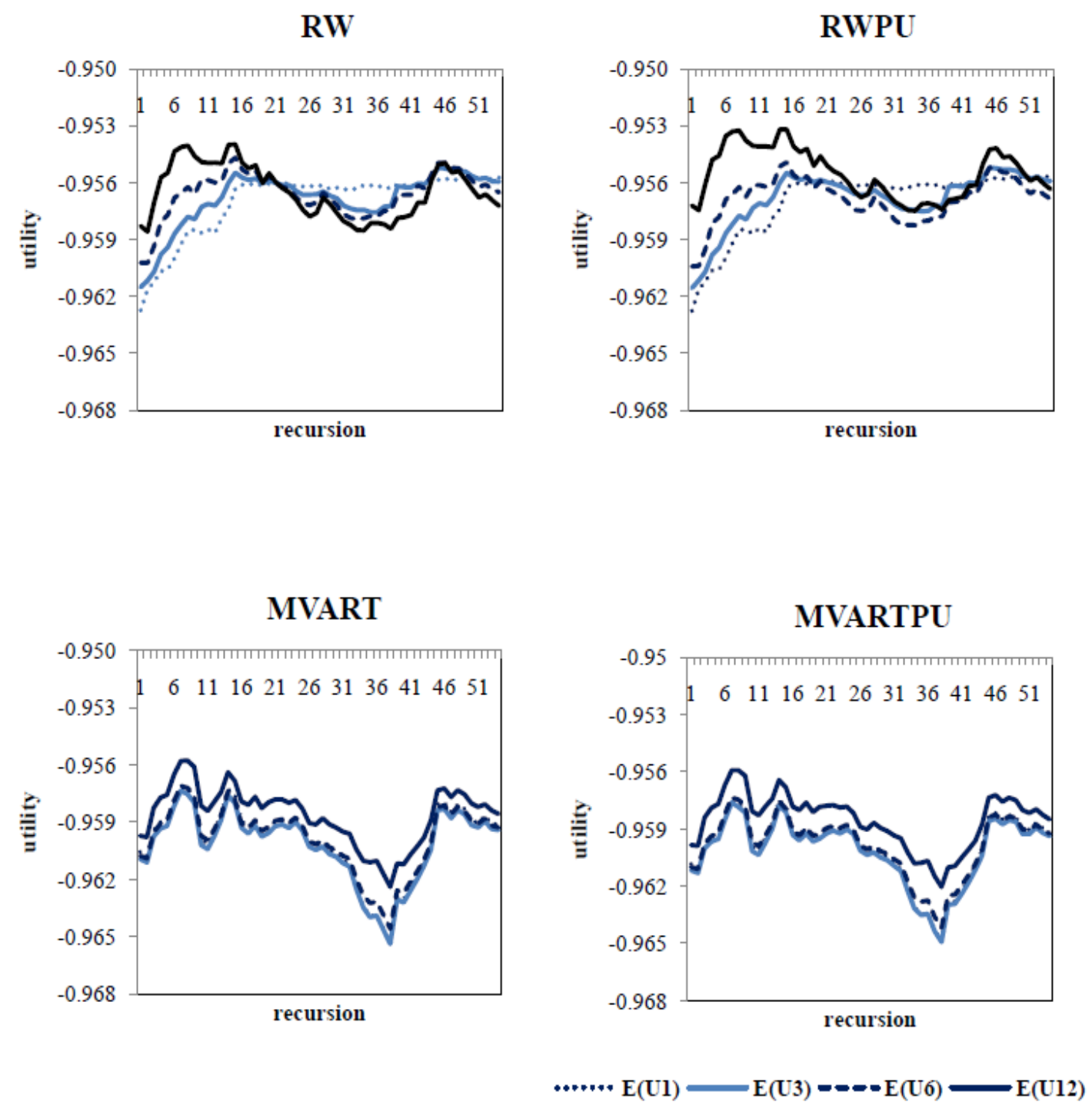
Figure 3: 1-month vs 3-month Allocations under the MVART Model, for $\mathrm{A}=2$

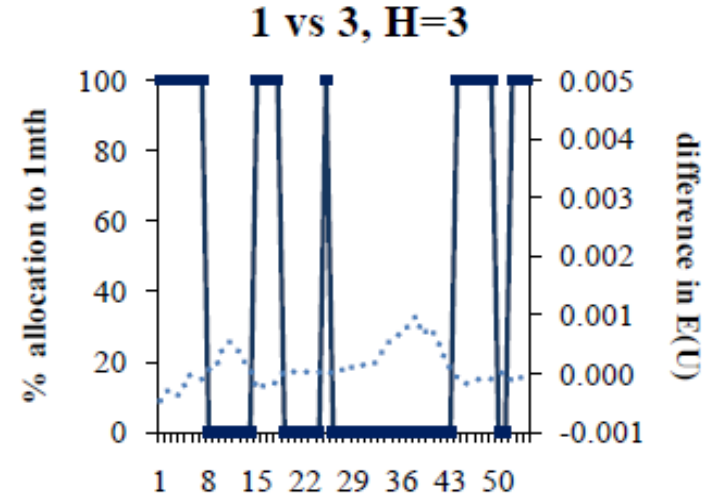

recursion

1 vs $3, \mathrm{H}=12$

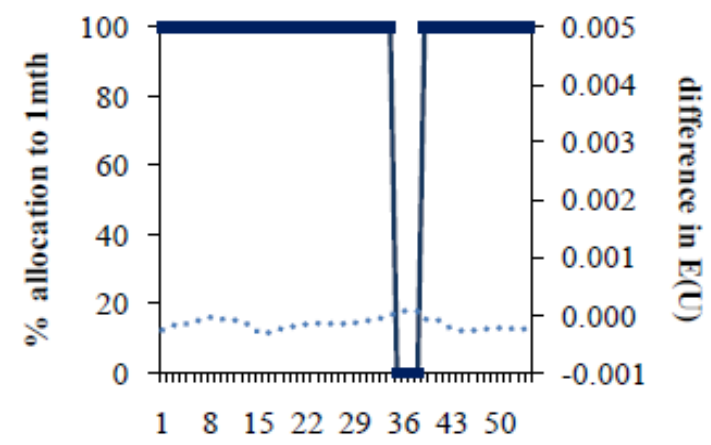

recursion
1 vs $3, \mathrm{H}=6$

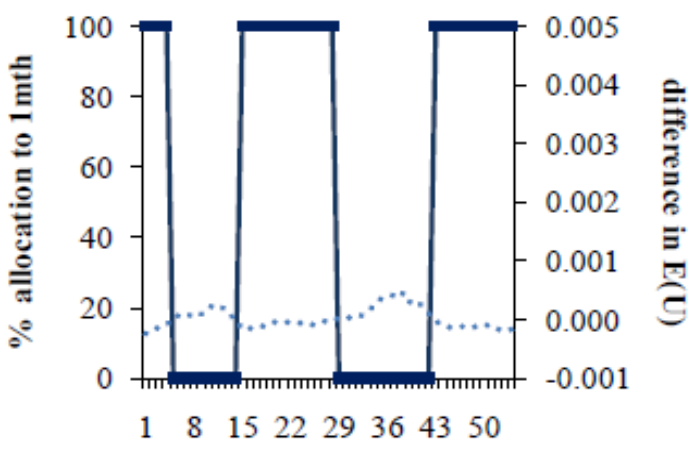

recursion

1 vs $3, \mathrm{H}=18$

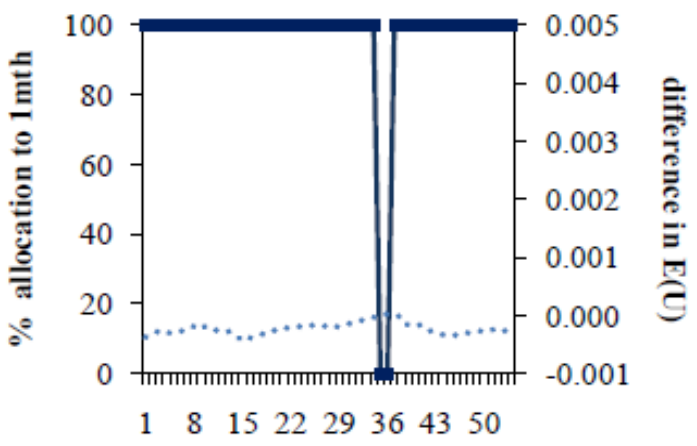

recursion

1 vs $3, \mathrm{H}=\mathbf{2 4}$

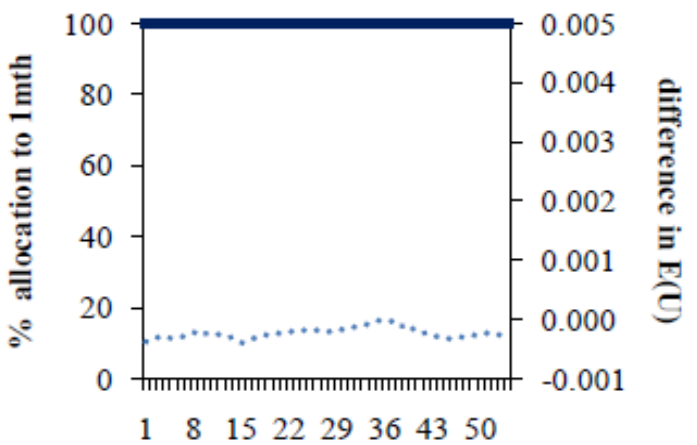

recursion 
Figure 4: Root Mean Squared Errors of Return

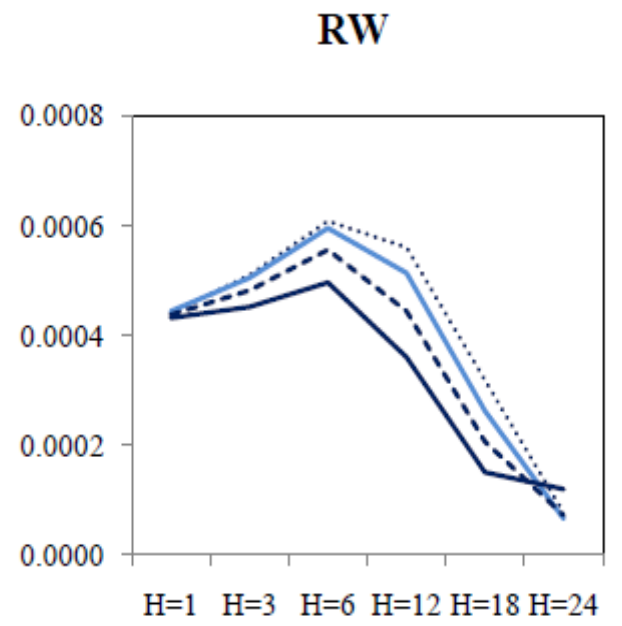

MVART

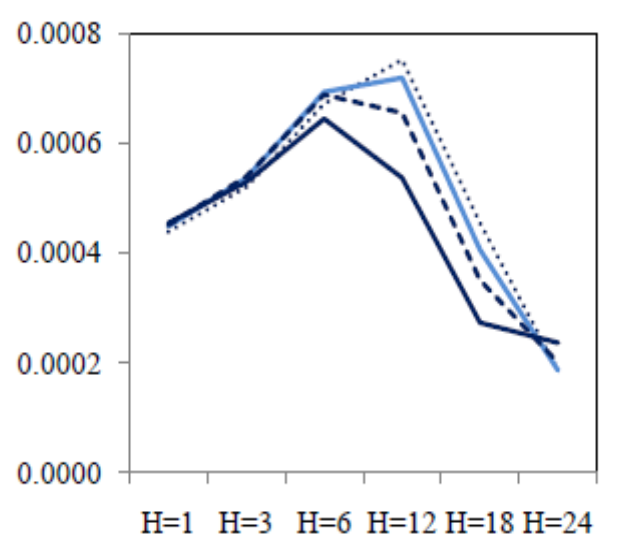

RWPU

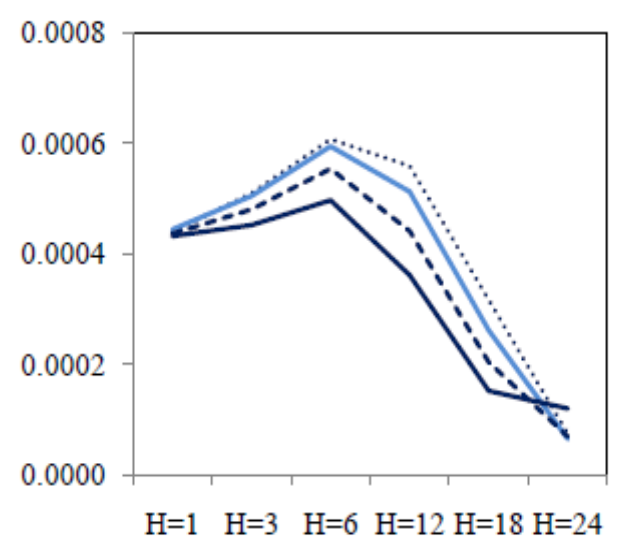

MVARTPU

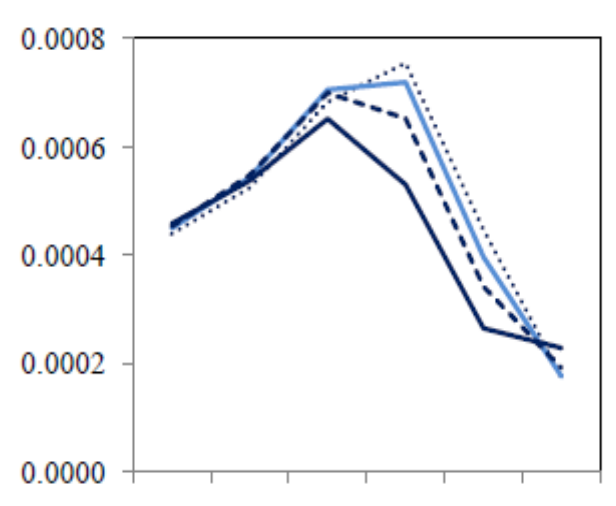

$\mathrm{H}=1 \quad \mathrm{H}=3 \quad \mathrm{H}=6 \quad \mathrm{H}=12 \quad \mathrm{H}=18 \quad \mathrm{H}=24$

RMSE of $r 1$

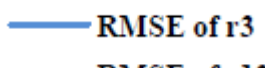

RMSE of $r 6$
- RMSE of r12 
Table 1: Estimation of Random Walk (RW) Model

\begin{tabular}{|c|c|c|c|c|}
\hline \hline Equation & $\Delta r_{t}^{1}$ & $\Delta r_{t}^{3}$ & $\Delta r_{t}^{6}$ & $\Delta r_{t}^{12}$ \\
\hline \hline$\mu$ & -0.000046 & -0.000043 & -0.000042 & -0.000044 \\
$\overline{R^{2}}$ & $(0.000041)$ & $(0.000033)$ & $(0.000038)$ & $(0.000049)$ \\
$\widehat{\sigma}$ & 0.000 & 0.000 & 0.000 & 0.000 \\
$e q^{n} L L$ & 0.0008 & 0.0006 & 0.0007 & 0.0009 \\
$\chi_{N}^{2}[2]$ & $358.23^{* * *}$ & 2219.11 & 2167.24 & 2067.53 \\
$\chi_{S C}^{2}[1]$ & 0.44 & $20.28^{* * *}$ & $76.42^{* * *}$ & $32.80^{* * *}$ \\
$\chi_{S C}^{2}[2]$ & 0.55 & $21.97^{* * *}$ & $11.20^{* * *}$ & 0.78 \\
$\chi_{S C}^{2}[6]$ & $20.73^{* * *}$ & $49.08^{* * *}$ & $33.35^{* * *}$ & 1.47 \\
$\chi_{S C}^{2}[12]$ & $29.45^{* * *}$ & $57.84^{* * *}$ & $40.17^{* * *}$ & $12.87^{* *}$ \\
\hline$\chi_{S C}^{2}[9]$ & \multicolumn{4}{|c|}{$38.15^{* * *}$} \\
$\chi_{S C}^{2}[12]$ & \multicolumn{4}{|c|}{12.34} \\
\hline \hline
\end{tabular}

Notes: Standard errors in parenthesis (.). The $\bar{R}^{2}$, standard error of the regression $(\widehat{\sigma}), \log$ likelihood of the equation (LL) are presented together with the chi-squared statistics for Breusch-Pagan Serial Correlation test (SC) and the Jarque-Bera Test for Normality $(\mathrm{N})$. The random walk with drift model assumes that $\Delta r_{t}^{n}=\mu+\epsilon_{t}$ for $n=1,3,6$ and 12 , and each is estimated over 1997 week 10 to 2004 week 18 (373 observations). Null rejected at ${ }^{* * *} 1 \%$ level, ${ }^{* *} 5 \%$ level, $* 10 \%$ level of significance. 
Table 2: Estimation of MVART(p) Model

\begin{tabular}{|c|c|c|c|c|}
\hline Equation & $s_{t}^{12,1}$ & $\bar{s}_{t}^{6,1}$ & $\bar{s}_{t}^{3,1}$ & $\Delta r_{t}^{1}$ \\
\hline$s_{t-1}^{12,1}$ & $\begin{array}{c}1.054^{* * *} \\
(0.216)\end{array}$ & $\begin{array}{c}0.289^{* *} \\
(0.144)\end{array}$ & $\begin{array}{l}0.159 \\
(0.099)\end{array}$ & $\begin{array}{l}0.172 \\
(0.151)\end{array}$ \\
\hline$s_{t-2}^{12,1}$ & $\begin{array}{l}0.214 \\
(0.259)\end{array}$ & $\begin{array}{c}-0.028 \\
(0.174)\end{array}$ & $\begin{array}{c}-0.054 \\
(0.109)\end{array}$ & $\begin{array}{c}-0.153 \\
(0.184)\end{array}$ \\
\hline$s_{t-3}^{12,1}$ & $\begin{array}{c}-0.489^{*} \\
(0.249)\end{array}$ & $\begin{array}{c}-0.435^{* *} \\
(0.176)\end{array}$ & $\begin{array}{c}-0.285^{* * *} \\
(0.110)\end{array}$ & $\begin{array}{l}0.089 \\
(0.137)\end{array}$ \\
\hline$s_{t-4}^{12,1}$ & $\begin{array}{l}0.337 \\
(0.264)\end{array}$ & $\begin{array}{l}0.232 \\
(0.186)\end{array}$ & $\begin{array}{l}0.115 \\
(0.112)\end{array}$ & $\begin{array}{l}0.056 \\
(0.192)\end{array}$ \\
\hline$s_{t-5}^{12,1}$ & $\begin{array}{c}-0.055 \\
(0.280)\end{array}$ & $\begin{array}{c}-0.009 \\
(0.198)\end{array}$ & $\begin{array}{l}0.047 \\
(0.124)\end{array}$ & $\begin{array}{l}0.294 \\
(0.245) \\
\end{array}$ \\
\hline$s_{t-6}^{12,1}$ & $\begin{array}{l}0.209 \\
(0.263)\end{array}$ & $\begin{array}{l}0.075 \\
(0.181)\end{array}$ & $\begin{array}{c}-0.020 \\
(0.118)\end{array}$ & $\begin{array}{c}-0.325^{*} \\
(0.178)\end{array}$ \\
\hline$s_{t-7}^{12,1}$ & $\begin{array}{c}-0.329 \\
(0.263)\end{array}$ & $\begin{array}{c}-0.329^{*} \\
(0.183)\end{array}$ & $\begin{array}{c}-0.225^{*} \\
(0.119)\end{array}$ & $\begin{array}{l}0.055 \\
(0.179)\end{array}$ \\
\hline$s_{t-8}^{12,1}$ & $\begin{array}{l}0.216 \\
(0.283)\end{array}$ & $\begin{array}{l}0.124 \\
(0.199)\end{array}$ & $\begin{array}{l}0.106 \\
(0.130)\end{array}$ & $\begin{array}{l}0.051 \\
(0.172)\end{array}$ \\
\hline$s_{t-9}^{12,1}$ & $\begin{array}{l}0.013 \\
(0.208)\end{array}$ & $\begin{array}{l}0.156 \\
(0.143)\end{array}$ & $\begin{array}{c}0.131^{*} \\
(0.094)\end{array}$ & $\begin{array}{c}-0.068 \\
(0.150)\end{array}$ \\
\hline$s_{t-1}^{6,1}$ & $\begin{array}{c}-0.407 \\
(0.514) \\
\end{array}$ & $\begin{array}{l}0.392 \\
(0.337) \\
\end{array}$ & $\begin{array}{c}-0.120 \\
(0.234)\end{array}$ & $\begin{array}{c}-0.540 \\
(0.357)\end{array}$ \\
\hline$s_{t-2}^{6,1}$ & $\begin{array}{c}-0.186 \\
(0.582)\end{array}$ & $\begin{array}{l}0.257 \\
(0.398) \\
\end{array}$ & $\begin{array}{l}0.247 \\
(0.268)\end{array}$ & $\begin{array}{l}0.250 \\
(0.449) \\
\end{array}$ \\
\hline$s_{t-3}^{6,1}$ & $\begin{array}{l}1.102^{*} \\
(0.595)\end{array}$ & $\begin{array}{c}0.942^{* *} \\
(0.422)\end{array}$ & $\begin{array}{c}0.543^{* *} \\
(0.266)\end{array}$ & $\begin{array}{c}-0.021 \\
(0.362)\end{array}$ \\
\hline$s_{t-4}^{6,1}$ & $\begin{array}{c}-0.771 \\
(0.621)\end{array}$ & $\begin{array}{c}-0.520 \\
(0.441)\end{array}$ & $\begin{array}{c}-0.245 \\
(0.278)\end{array}$ & $\begin{array}{c}-0.379 \\
(0.464)\end{array}$ \\
\hline$s_{t-5}^{6,1}$ & $\begin{array}{l}0.234 \\
(0.664) \\
\end{array}$ & $\begin{array}{l}0.123 \\
(0.465)\end{array}$ & $\begin{array}{c}-0.068 \\
(0.289)\end{array}$ & $\begin{array}{c}-0.471 \\
(0.538)\end{array}$ \\
\hline$s_{t-6}^{6,1}$ & $\begin{array}{c}-0.159 \\
(0.614)\end{array}$ & $\begin{array}{c}-0.030 \\
(0.426)\end{array}$ & $\begin{array}{l}0.122 \\
(0.276)\end{array}$ & $\begin{array}{l}0.385 \\
(0.434)\end{array}$ \\
\hline$s_{t-7}^{6,1}$ & $\begin{array}{c}0.235 \\
(0.61) \\
\end{array}$ & $\begin{array}{l}0.373 \\
(0.411) \\
\end{array}$ & $\begin{array}{l}0.231 \\
(0.256) \\
\end{array}$ & $\begin{array}{l}0.236 \\
(0.402) \\
\end{array}$ \\
\hline$s_{t-8}^{6,1}$ & $\begin{array}{c}-0.242 \\
(0.659)\end{array}$ & $\begin{array}{c}-0.099 \\
(0.454)\end{array}$ & $\begin{array}{c}-0.068 \\
(0.298)\end{array}$ & $\begin{array}{c}-0.633 \\
(0.443)\end{array}$ \\
\hline$s_{t-9}^{6,1}$ & $\begin{array}{c}-0.068 \\
(0.485)\end{array}$ & $\begin{array}{c}-0.383 \\
(0.338)\end{array}$ & $\begin{array}{c}-0.337 \\
(0.232)\end{array}$ & $\begin{array}{l}0.369 \\
(0.357) \\
\end{array}$ \\
\hline$s_{t-1}^{3,1}$ & $\begin{array}{l}0.081 \\
(0.467)\end{array}$ & $\begin{array}{c}-0.060 \\
(0.283) \\
\end{array}$ & $\begin{array}{c}0.525^{* * *} \\
(0.184)\end{array}$ & $\begin{array}{c}1.126^{* * *} \\
(0.338)\end{array}$ \\
\hline$s_{t-2}^{3,1}$ & $\begin{array}{l}0.089 \\
(0.538) \\
\end{array}$ & $\begin{array}{c}-0.125 \\
(0.360)\end{array}$ & $\begin{array}{c}-0.095 \\
(0.242)\end{array}$ & $\begin{array}{c}-0.391 \\
(0.393)\end{array}$ \\
\hline$s_{t-3}^{3,1}$ & $\begin{array}{c}-1.040^{*} \\
(0.570)\end{array}$ & $\begin{array}{c}-0.883^{* *} \\
(0.406)\end{array}$ & $\begin{array}{c}-0.489^{*} \\
(0.255)\end{array}$ & $\begin{array}{l}0.061 \\
(0.358) \\
\end{array}$ \\
\hline$s_{t-4}^{3,1}$ & $\begin{array}{l}0.786 \\
(0.606) \\
\end{array}$ & $\begin{array}{l}0.559 \\
(0.419) \\
\end{array}$ & $\begin{array}{l}0.251 \\
(0.266)\end{array}$ & $\begin{array}{l}0.512 \\
(0.424) \\
\end{array}$ \\
\hline$s_{t-5}^{3,1}$ & $\begin{array}{l}0.034 \\
(0.607)\end{array}$ & $\begin{array}{l}0.052 \\
(0.443)\end{array}$ & $\begin{array}{l}0.183 \\
(0.288)\end{array}$ & $\begin{array}{c}-0.145 \\
(0.478)\end{array}$ \\
\hline$s_{t-6}^{3,1}$ & $\begin{array}{c}-0.546 \\
(0.546) \\
\end{array}$ & $\begin{array}{c}-0.468 \\
(0.381) \\
\end{array}$ & $\begin{array}{c}-0.371 \\
(0.256) \\
\end{array}$ & $\begin{array}{l}0.380 \\
(0.413) \\
\end{array}$ \\
\hline$s_{t-7}^{3,1}$ & $\begin{array}{l}0.080 \\
(0.514)\end{array}$ & $\begin{array}{c}-0.089 \\
(0.344)\end{array}$ & $\begin{array}{c}-0.037 \\
(0.206)\end{array}$ & $\begin{array}{c}-0.4512 \\
(0.347)\end{array}$ \\
\hline
\end{tabular}


Table 3: Estimation of MVART(p) Model (continued)

\begin{tabular}{|c|c|c|c|c|}
\hline$s_{t-8}^{3,1}$ & $\begin{array}{l}-0.074 \\
(0.600)\end{array}$ & $\begin{array}{c}-0.025 \\
(0.388)\end{array}$ & $\begin{array}{c}-0.024 \\
(0.260)\end{array}$ & $\begin{array}{c}0.909^{* *} \\
(0.441)\end{array}$ \\
\hline$s_{t-9}^{3,1}$ & $\begin{array}{l}0.191 \\
(0.453)\end{array}$ & $\begin{array}{l}0.402 \\
(0.325)\end{array}$ & $\begin{array}{l}0.358 \\
(0.220)\end{array}$ & $\begin{array}{c}-0.543^{*} \\
(0.319)\end{array}$ \\
\hline$\Delta r_{t-1}^{1}$ & $\begin{array}{l}0.034 \\
(0.114)\end{array}$ & $\begin{array}{l}0.053 \\
(0.083)\end{array}$ & $\begin{array}{l}0.032 \\
(0.054)\end{array}$ & $\begin{array}{l}0.089 \\
(0.085)\end{array}$ \\
\hline$\Delta r_{t-2}^{1}$ & $\begin{array}{l}0.167^{*} \\
(0.094)\end{array}$ & $\begin{array}{c}0.171^{* *} \\
(0.069)\end{array}$ & $\begin{array}{c}0.127^{* * *} \\
(0.047)\end{array}$ & $\begin{array}{c}-0.175^{* * *} \\
(0.061)\end{array}$ \\
\hline$\Delta r_{t-3}^{1}$ & $\begin{array}{c}-0.016 \\
(0.096)\end{array}$ & $\begin{array}{l}0.015 \\
(0.065)\end{array}$ & $\begin{array}{l}0.024 \\
(0.038)\end{array}$ & $\begin{array}{c}-0.023 \\
(0.056)\end{array}$ \\
\hline$\Delta r_{t-4}^{1}$ & $\begin{array}{l}0.065 \\
(0.104)\end{array}$ & $\begin{array}{l}0.080 \\
(0.068)\end{array}$ & $\begin{array}{l}0.041 \\
(0.042)\end{array}$ & $\begin{array}{l}0.066 \\
(0.073)\end{array}$ \\
\hline$\Delta r_{t-5}^{1}$ & $\begin{array}{l}0.255 \\
(0.155)\end{array}$ & $\begin{array}{c}0.263^{* *} \\
(0.104)\end{array}$ & $\begin{array}{c}0.184^{* * *} \\
(0.059)\end{array}$ & $\begin{array}{c}-0.176^{* *} \\
(0.078)\end{array}$ \\
\hline$\Delta r_{t-6}^{1}$ & $\begin{array}{c}-0.018 \\
(0.091)\end{array}$ & $\begin{array}{c}-0.003 \\
(0.070)\end{array}$ & $\begin{array}{c}-0.005 \\
(0.047)\end{array}$ & $\begin{array}{l}0.088 \\
(0.067)\end{array}$ \\
\hline$\Delta r_{t-7}^{1}$ & $\begin{array}{l}0.045 \\
(0.93)\end{array}$ & $\begin{array}{l}0.028 \\
(0.064)\end{array}$ & $\begin{array}{l}-0.001 \\
(0.040)\end{array}$ & $\begin{array}{c}-0.066 \\
(0.067)\end{array}$ \\
\hline$\Delta r_{t-8}^{1}$ & $\begin{array}{c}-0.069 \\
(0.092)\end{array}$ & $\begin{array}{c}-0.034 \\
(0.059)\end{array}$ & $\begin{array}{l}-0.021 \\
(0.035)\end{array}$ & $\begin{array}{l}0.090 \\
(0.071)\end{array}$ \\
\hline$\Delta r_{t-9}^{1}$ & $\begin{array}{c}-0.111 \\
(0.069)\end{array}$ & $\begin{array}{c}-0.086^{*} \\
(0.046)\end{array}$ & $\begin{array}{c}-0.044 \\
(0.030)\end{array}$ & $\begin{array}{l}0.040 \\
(0.052)\end{array}$ \\
\hline inpt & $\begin{array}{c}-0.0001 \\
(0.00007)\end{array}$ & $\begin{array}{c}-0.00009^{*} \\
(0.00005)\end{array}$ & $\begin{array}{c}-0.00004 \\
(0.00003)\end{array}$ & $\begin{array}{c}0.000005 \\
(0.00004)\end{array}$ \\
\hline$\overline{R^{2}}$ & 0.934 & 0.901 & 0.829 & 0.273 \\
\hline$\widehat{\sigma}$ & 0.001 & 0.0007 & 0.0004 & 0.0007 \\
\hline$F[36,327]$ & $144.42^{* * *}$ & $93.27^{* * *}$ & $50.02^{* * *}$ & $4.80^{* * *}$ \\
\hline$e q^{n} L L$ & 2028.0 & 2163.5 & 2337.9 & 2172.6 \\
\hline system $L L$ & \multicolumn{4}{|c|}{9659.1} \\
\hline$\chi_{N}^{2}[8]$ & \multicolumn{4}{|c|}{$35.03^{* * *}$} \\
\hline$\chi_{H}^{2}[720]$ & \multicolumn{4}{|c|}{$910.12^{* * *}$} \\
\hline$\chi_{S C}^{2}[16]$ & \multicolumn{4}{|c|}{18.48} \\
\hline
\end{tabular}

Notes: Standard errors in parenthesis. A MVART(9) is estimated over 1997 week 10 to 2004 week 18 (364 observations). The regressions are estimated with Newey-West heteroskedastic and autocorrelation corrected errors. The $\bar{R}^{2}$, standard error of the regression $(\widehat{\sigma})$, F-statistic to test the joint significance of the estimated coefficients and the log likelihood of the equation (LL) are presented together with the model diagnostic tests which are all carried out on the VAR residuals. No roots of the characteristic polynomial lie outside the unit circle so the VAR is stable. Chi-squared statistics presented for: (N) the VAR Residual Normality Test; (H) the VAR Residual Heteroskedasticity Test, and (SC) the VAR Residual Serial Correlation LM Test for the null of no serial correlation at lag 9 . Null rejected at *** $1 \%$ level, $* * 5 \%$ level, $* 10 \%$ level of significance. 
Table 4: Root Mean Squared Errors of Returns

(a) 1-month returns $\left(r_{t}^{1}\right)$

\begin{tabular}{|l|c|c|c|c|c|c|}
\hline \hline \multicolumn{1}{|c|}{ Model } & $H=1$ & $H=3$ & $H=6$ & $H=12$ & $H=18$ & $H=24$ \\
\hline \hline RW & 0.000439 & 0.000510 & 0.000608 & 0.000560 & 0.000318 & 0.000076 \\
MVART & 0.000438 & 0.000519 & 0.000671 & 0.000751 & 0.000454 & 0.000184 \\
RWPU & 0.000439 & 0.000509 & 0.000607 & 0.000558 & 0.000316 & 0.000074 \\
MVARTPU & 0.000440 & 0000525 & 0.000683 & 0.000755 & 0.000447 & 0.000175 \\
\hline \hline
\end{tabular}

(b) 3-month returns $\left(r_{t}^{3}\right)$

\begin{tabular}{|l|c|c|c|c|c|c|}
\hline \hline \multicolumn{1}{|c|}{ Model } & $H=1$ & $H=3$ & $H=6$ & $H=12$ & $H=18$ & $H=24$ \\
\hline \hline RW & 0.000444 & 0.000505 & 0.000595 & 0.000513 & 0.000262 & 0.000065 \\
MVART & 0.000447 & 0.000535 & 0.000692 & 0.000718 & 0.000404 & 0.000185 \\
RWPU & 0.000444 & 0.000504 & 0.000594 & 0.000512 & 0.000262 & 0.000065 \\
MVARTPU & 0.000450 & 0.000543 & 0.000706 & 0.000720 & 0.000397 & 0.0001762 \\
\hline \hline
\end{tabular}

(c) 6-month returns $\left(r_{t}^{6}\right)$

\begin{tabular}{|l|c|c|c|c|c|c|}
\hline \hline \multicolumn{1}{|c|}{ Model } & $H=1$ & $H=3$ & $H=6$ & $H=12$ & $H=18$ & $H=24$ \\
\hline \hline RW & 0.000437 & 0.00482 & 0.000556 & 0.000444 & 0.000206 & 0.000071 \\
MVART & 0.000449 & 0.000538 & 0.000687 & 0.000654 & 0.000350 & 0.000199 \\
RWPU & 0.000437 & 0.000481 & 0.000554 & 0.000441 & 0.000204 & 0.000069 \\
MVARTPU & 0.000453 & 0.000547 & 0.000699 & 0.000652 & 0.000342 & 0.000191 \\
\hline \hline
\end{tabular}

(d) 12-month returns $\left(r_{t}^{12}\right)$

\begin{tabular}{|l|c|c|c|c|c|c|}
\hline \hline \multicolumn{1}{|c|}{ Model } & $H=1$ & $H=3$ & $H=6$ & $H=12$ & $H=18$ & $H=24$ \\
\hline \hline RW & 0.000431 & 0.000451 & 0.000496 & 0.000360 & 0.000150 & 0.000119 \\
MVART & 0.000454 & 0.000528 & 0.000643 & 0.000536 & 0.000272 & 0.000236 \\
RWPU & 0.000432 & 0.000452 & 0.000496 & 0.000361 & 0.000151 & 0.000120 \\
MVARTPU & 0.000458 & 0.000538 & 0.000652 & 0.000530 & 0.000265 & 0.000229 \\
\hline \hline
\end{tabular}

Notes: The RMSEs are computed for each model for the horizons $\mathrm{H}=1,3,6,12,18,24$ months, and for each model as follows $\sqrt{\frac{\sum_{i=1}^{54}\left(r_{T+H}-\widehat{r}_{T+H}\right)_{i}}{54}}$, where $r_{T+H}$ is the actual monthly return i.e. $r_{t}^{1}, r_{t}^{3}, r_{t}^{6}, r_{t}^{12}, \widehat{r}_{T+H}$ is the forecast and the difference between the two $\left(r_{T+H}-\widehat{r}_{T+H}\right)$ is computed for each recursion $i$, there are 54 weekly recursions. The RW and MVART models are estimated subject to stochastic uncertainty only, the RWPU and MVARTPU models consider parameter uncertainty too. 
Table 5: Ratio of RMSEs of Returns

(a) 1-month returns $\left(r_{t}^{1}\right)$

\begin{tabular}{|l|c|c|c|c|c|c|}
\hline \hline \multicolumn{1}{|c|}{ Model } & $H=1$ & $H=3$ & $H=6$ & $H=12$ & $H=18$ & $H=24$ \\
\hline \hline RW & 1.0000 & 1.0000 & 1.0000 & 1.0000 & 1.0000 & 1.0000 \\
MVART & 0.9957 & 1.0175 & 1.1026 & 1.3409 & 1.4268 & 2.4348 \\
RWPU & 0.9997 & 0.9991 & 0.9982 & 0.9966 & 0.9951 & 0.9831 \\
MVARTPU & 1.0002 & 1.0297 & 1.1239 & 1.3480 & 1.4051 & 2.3168 \\
\hline
\end{tabular}

(b) 3-month returns $\left(r_{t}^{3}\right)$

\begin{tabular}{|l|c|c|c|c|c|c|}
\hline \hline \multicolumn{1}{|c|}{ Model } & $H=1$ & $H=3$ & $H=6$ & $H=12$ & $H=18$ & $H=24$ \\
\hline \hline RW & 1.0000 & 1.0000 & 1.0000 & 1.0000 & 1.0000 & 1.0000 \\
MVART & 1.0079 & 1.0605 & 1.1635 & 1.3995 & 1.5427 & 2.8367 \\
RWPU & 0.9998 & 0.9994 & 0.9989 & 0.9981 & 0.9981 & 0.9890 \\
MVARTPU & 1.0141 & 1.0765 & 1.1860 & 1.4021 & 1.5145 & 2.7034 \\
\hline \hline
\end{tabular}

(c) 6-month returns $\left(r_{t}^{6}\right)$

\begin{tabular}{|l|c|c|c|c|c|c|}
\hline \hline \multicolumn{1}{|c|}{ Model } & $H=1$ & $H=3$ & $H=6$ & $H=12$ & $H=18$ & $H=24$ \\
\hline \hline RW & 1.0000 & 1.0000 & 1.0000 & 1.0000 & 1.0000 & 1.0000 \\
MVART & 1.0287 & 1.1166 & 1.2365 & 1.4733 & 1.6996 & 2.7928 \\
RWPU & 0.9994 & 0.9983 & 0.9969 & 0.9940 & 0.9909 & 0.9700 \\
MVARTPU & 1.0372 & 1.1366 & 1.2588 & 1.4689 & 1.6629 & 2.6872 \\
\hline \hline
\end{tabular}

(d) 12-month returns $\left(r_{t}^{12}\right)$

\begin{tabular}{|l|c|c|c|c|c|c|}
\hline \hline \multicolumn{1}{|c|}{ Model } & $H=1$ & $H=3$ & $H=6$ & $H=12$ & $H=18$ & $H=24$ \\
\hline \hline RW & 1.0000 & 1.0000 & 1.0000 & 1.0000 & 1.0000 & 1.0000 \\
MVART & 1.0518 & 1.1697 & 1.2972 & 1.4897 & 1.8120 & 1.9793 \\
RWPU & 1.0002 & 1.0002 & 1.0007 & 1.0025 & 1.0081 & 1.0048 \\
MVARTPU & 1.0620 & 1.1916 & 1.3144 & 1.4733 & 1.7645 & 1.9198 \\
\hline \hline
\end{tabular}

Notes: The above ratios are that of the RMSE for each model to the RMSE of the RW model, which is taken as the benchmark. 
Table 6: Effects on Allocation

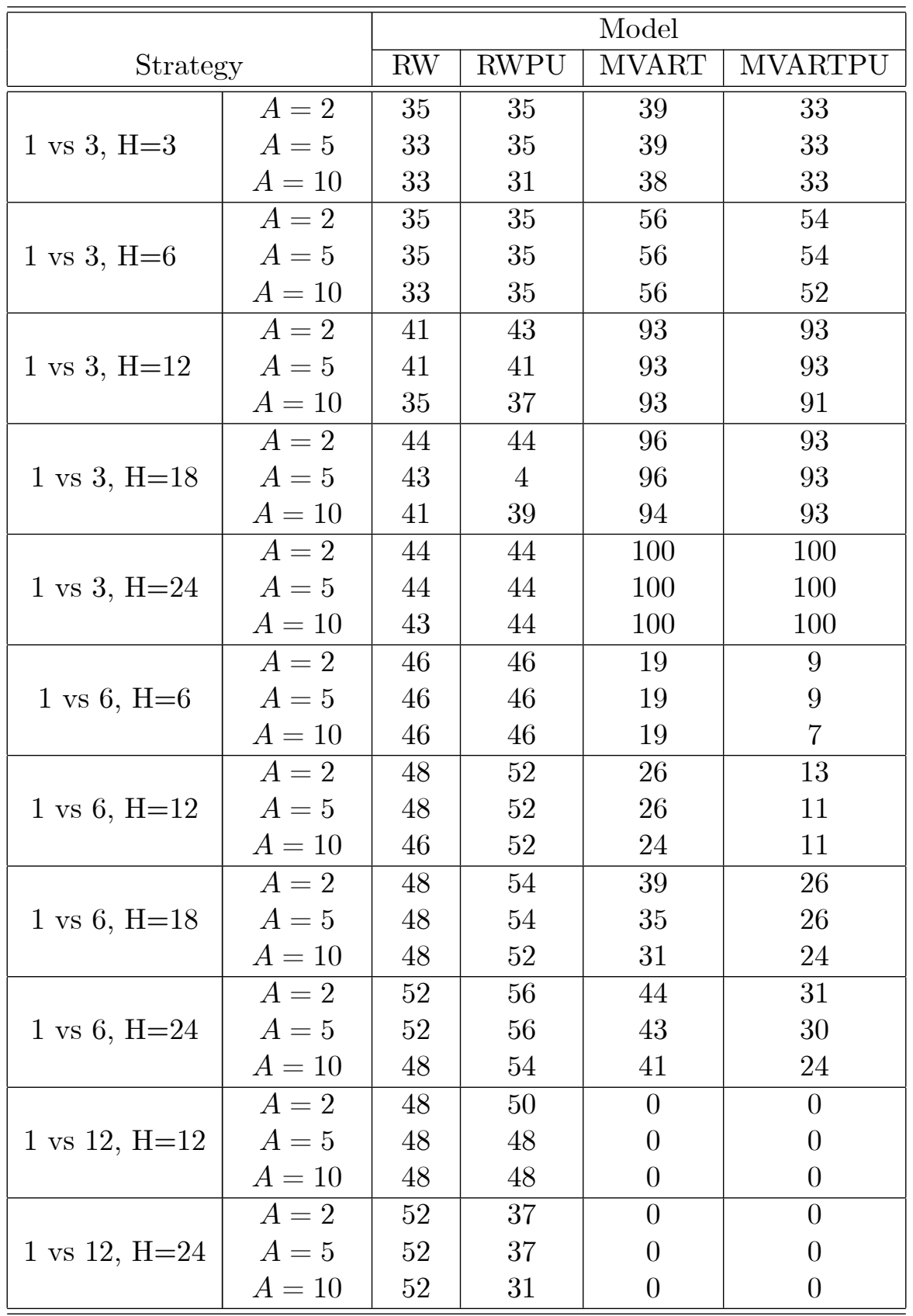

Notes: Here under each portfolio combination, for a given $\mathrm{A}, \mathrm{H}$ and model, the table gives as a percentage the number of times out of the 54 recursions the investor allocates everything to the 1-month bill. 
Table 7: Realised Wealth under each 1-month vs n-month Strategy, for $\mathrm{A}=2$

(a) 1-month vs 3 -month

\begin{tabular}{|c|c|c|c|c|c|}
\hline \hline Position & $H=3$ & $H=6$ & $H=12$ & $H=18$ & $H=24$ \\
\hline \hline 1st & A1 & A1 & A1 & A1 & A1 \\
& 1.046746 & 1.046877 & 1.04654 & 1.046072 & 1.046091 \\
\hline \multirow{2}{*}{ 2nd } & RW & RWPU & MVARTPU & MVART & MVARTPU \\
& 1.046740 & 1.046804 & 1.046511 & 1.046062 & 1.046091 \\
\hline \multirow{2}{*}{ 3rd } & RWPU & RW & MVART & MVARTPU & MVART \\
& 1.046740 & 1.046796 & 1.046511 & 1.046044 & 1.046091 \\
\hline \multirow{2}{*}{4 th } & MVART & MVART & RWPU & RWPU & RW \\
& 1.046511 & 1.046774 & 1.046432 & 1.045910 & 1.046010 \\
\hline 5th & A3 & MVRTPU & RW & RW & RWPU \\
& 1.046509 & 1.046769 & 1.046431 & 1.045910 & 1.046009 \\
\hline 6th & MVARTPU & A3 & A3 & A3 & A3 \\
& 1.046505 & 1.046649 & 1.046252 & 1.045755 & 1.045967 \\
\hline \hline
\end{tabular}

(b) 1-month vs 6-month

\begin{tabular}{|c|c|c|c|c|}
\hline \hline Position & $H=6$ & $H=12$ & $H=18$ & $H=24$ \\
\hline 1st & RW & A1 & A1 & A1 \\
& 1.047030 & 1.046877 & 1.046544 & 1.046072 \\
\hline \multirow{2}{*}{$2 \mathrm{nd}$} & RWPU & RWPU & RWPU & RWPU \\
& 1.047027 & 1.04638 & 1.045804 & 1.045836 \\
\hline \multirow{2}{*}{ 3rd } & A1 & RW & RW & RW \\
& 1.046746 & 1.046372 & 1.045792 & 1.045828 \\
\hline \multirow{2}{*}{4 th } & MVARTPU & MVARTPU & MVART & MVART \\
& 1.046634 & 1.046079 & 1.045625 & 1.045740 \\
\hline 5 th & A6 & MVART & MVARTPU & MVARTPU \\
& 1.046609 & 1.046078 & 1.045542 & 1.045666 \\
\hline \multirow{2}{*}{6 th } & MVART & A6 & A6 & A6 \\
& 1.046602 & 1.046041 & 1.045444 & 1.045548 \\
\hline \hline
\end{tabular}

(c) 1-month vs 12 -month

\begin{tabular}{|c|c|c|}
\hline \hline Position & $H=12$ & $H=24$ \\
\hline \hline 1 st & RWPU & A1 \\
& 1.047033 & 1.046072 \\
\hline \multirow{2}{*}{ nd } & RW & RW \\
& 1.047027 & 1.045806 \\
\hline 3rd & A12 & RWPU \\
& 1.046566 & 1.045629 \\
\hline 4 th & MVATPU & MVARTPU \\
& 1.046566 & 1.044899 \\
\hline 5 th & MVART & MVART \\
& 1.046566 & 1.044899 \\
\hline 6 th & A1 & A12 \\
& 1.046746 & 1.044889 \\
\hline
\end{tabular}

Notes: The realised wealths above are the end-of-investment horizon wealths that the investor would have achieved over 2004 week 19 to 2007 week 19 had she allocated according to the optimal weights for each model, A and H. These end-of-investment horizon wealths have been averaged over the 54 recursions. The realised wealth for each model are ranked in descending order, for a particular $\mathrm{A}$ and $\mathrm{H}$. The tables above show how the two models, RW and MVART, without and with parameter uncertainty perform, together with the lazy strategies in terms of their achieved realised wealths. The actual realised wealths are given below the model code. 'A1' is the 'all in 1-month' and 'An' is the 'all in n-month' lazy strategy for $\mathrm{n}=3,6$ and 12 months. The realised wealths are presented for $\mathrm{A}=2$ only because the wealths under $\mathrm{A}=5$ and 10 are not significantly different. 
Table 8: Ratios of Realised Wealth

(a) 1-month vs 3-month

\begin{tabular}{|l|c|c|c|c|c|}
\hline \hline \multicolumn{1}{|c|}{ Model } & $H=3$ & $H=6$ & $H=12$ & $H=18$ & $H=24$ \\
\hline \hline RW & 1.0000 & 1.0000 & 1.0000 & 1.0000 & 1.0000 \\
RWPU & 1.0000 & 1.0000 & 1.0000 & 1.0000 & 1.0000 \\
MVART & 0.9998 & 1.0000 & 1.0001 & 1.0001 & 1.0001 \\
MVARTPU & 0.9998 & 1.0000 & 1.0001 & 1.0001 & 1.0001 \\
\hline \hline
\end{tabular}

(b) 1-month vs 6-month

\begin{tabular}{|l|c|c|c|c|}
\hline \hline \multicolumn{1}{|c|}{ Model } & $H=6$ & $H=12$ & $H=18$ & $H=24$ \\
\hline \hline RW & 1.0000 & 1.0000 & 1.0000 & 1.0000 \\
RWPU & 1.0000 & 1.0000 & 1.0000 & 1.0000 \\
MVART & 0.9996 & 0.9997 & 0.9998 & 0.9999 \\
MVARTPU & 0.9996 & 0.9997 & 0.9998 & 0.9998 \\
\hline \hline
\end{tabular}

(c) 1 -month vs 12 -month

\begin{tabular}{l|c|c|}
\hline \hline \multicolumn{1}{|c|}{ Model } & $H=12$ & $H=24$ \\
\hline \hline RW & 1.0000 & 1.0000 \\
RWPU & 1.0000 & 0.9998 \\
MVART & 0.9996 & 0.9991 \\
MVARTPU & 0.9996 & 0.9991 \\
\hline \hline
\end{tabular}

Notes: Ratio of Realised Wealths under each model to that of the RW model, are presented for $\mathrm{A}=2$ only because the Ratios under $\mathrm{A}=5$ and 10 are not significantly different. 